\title{
Dynamic model validation and advanced polymer control for rotating belt filtration as primary treatment of domestic wastewaters
}

Boiocchi, Riccardo; Behera, Chitta Ranjan; Sherratt, Anthony; DeGroot, Christopher T.; Gernaey, Krist V.; Sin, Gürkan; Santoro, Domenico

Published in:

Chemical Engineering Science

Link to article, DOI:

10.1016/j.ces.2020.115510

Publication date:

2020

Document Version

Peer reviewed version

Link back to DTU Orbit

Citation (APA):

Boiocchi, R., Behera, C. R., Sherratt, A., DeGroot, C. T., Gernaey, K. V., Sin, G., \& Santoro, D. (2020). Dynamic model validation and advanced polymer control for rotating belt filtration as primary treatment of domestic wastewaters. Chemical Engineering Science, 217, [115510]. https://doi.org/10.1016/j.ces.2020.115510

\section{General rights}

Copyright and moral rights for the publications made accessible in the public portal are retained by the authors and/or other copyright owners and it is a condition of accessing publications that users recognise and abide by the legal requirements associated with these rights.

- Users may download and print one copy of any publication from the public portal for the purpose of private study or research.

- You may not further distribute the material or use it for any profit-making activity or commercial gain

- You may freely distribute the URL identifying the publication in the public portal 


\section{Journal Pre-proofs}

Dynamic model validation and advanced polymer control for rotating belt filtration as primary treatment of domestic wastewaters

Riccardo Boiocchi, Chitta Ranjan Behera, Anthony Sherratt, Christopher T.

DeGroot, Krist V. Gernaey, Gürkan Sin, Domenico Santoro

PII:

S0009-2509(20)30042-7

DOI:

https://doi.org/10.1016/j.ces.2020.115510

Reference:

CES 115510

To appear in:

\section{Chemical Engineering Science}

Received Date:

8 July 2019

Revised Date:

22 November 2019

Accepted Date:

24 January 2020

Please cite this article as: R. Boiocchi, C. Ranjan Behera, A. Sherratt, C.T. DeGroot, K.V. Gernaey, G. Sin, D. Santoro, Dynamic model validation and advanced polymer control for rotating belt filtration as primary treatment of domestic wastewaters, Chemical Engineering Science (2020), doi: https://doi.org/10.1016/j.ces.2020.115510

This is a PDF file of an article that has undergone enhancements after acceptance, such as the addition of a cover page and metadata, and formatting for readability, but it is not yet the definitive version of record. This version will undergo additional copyediting, typesetting and review before it is published in its final form, but we are providing this version to give early visibility of the article. Please note that, during the production process, errors may be discovered which could affect the content, and all legal disclaimers that apply to the journal pertain.

(C) 2020 Published by Elsevier Ltd. 


\section{Dynamic model validation and advanced polymer control for rotating}

\section{belt filtration as primary treatment of domestic wastewaters}

Riccardo Boiocchi $^{\left({ }^{a}\right)}$, Chitta Ranjan Behera ${ }^{(b)}$, Anthony Sherratt ${ }^{(c)}$, Christopher T. DeGroot ${ }^{(c)}$, Krist V. Gernaey ${ }^{(b)}$, Gürkan Sin ${ }^{(b)}$, Domenico Santoro ${ }^{(d) *}$

*Corresponding author. E-mail address: dsantoro@trojanuv.com.

(a) Department of Civil and Environmental Engineering, University of Alberta, Edmonton (AB T6G 2E1), Canada

(b) Process and Systems Engineering Center (PROSYS), Department of Chemical and Biochemical Engineering, Technical University of Denmark, 2800 Kgs. Lyngby, Denmark

(c) Department of Mechanical and Materials Engineering, Western University, London (ON N6A 5B9), Canada

(d) Research and development department, Trojan Technologies, London (ON N5V 4T7), Canada

Keywords: wastewater; rotating belt filters; primary treatment; plant-wide assessment; benchmark; model validation.

\section{Nomenclature and symbols}

A

$\mathrm{A}_{\text {filtr }}$

AOB

AS

$a_{\text {sludge }}$
Height of the column test associated to the sieving process

Filtration area

Ammonia Oxidizing Bacteria

Activated Sludge

Multiplication coefficient for sludge concentration expression 

Filtration rate associated to the mesh sieving process
B
Height of the column test associated to the cake filtration process
BeltSpeed
Rotational belt speed of the filter
BeltSpeed $_{\mathrm{A}} \quad$ Actuated belt speed of the filter
BeltSpeedMax Maximum value of belt speed
BeltSpeedMin Minimum value of belt speed
BeltSpeed $_{0} \quad$ Nominal value of belt speed
$b_{\text {sludge }}$
Exponent for sludge concentration expression
BSM2
Benchmark Simulation Model No2
$\beta$
Filtration rate associated to the cake filtration process
$C_{d}^{\text {of }}$
Discharge coefficient for the overflow flow rate
$\mathrm{C}_{\mathrm{d}}^{\text {out,weir }}$
Discharge coefficient for the flow rate leaving the RBF system
$\gamma$
Exponent for varying effect of cake resistance on filtered TSS
$\Delta x_{i}$
Length of the element into which the filter is discretized
$\Delta \mathrm{p}$
Pressure difference
$\mathrm{e}_{\text {BeltSpeed }}$
Belt speed error
$\mathrm{e}_{\mathrm{hUP}}$
Upstream height error
$\mathrm{e}_{\text {TSSfiltered }}$
Filtered TSS error
f
Motor frequency
HB
Heterotrophic Bacteria
$\mathrm{h}$
Height of the column test
$\mathrm{h}_{\text {down }}$
Downstream height
$\mathrm{h}_{\mathrm{of}}$
Height of the foot of the overflow channel 


\begin{tabular}{|c|c|}
\hline$h_{\text {up }}$ & Upstream height \\
\hline $\mathrm{h}_{\text {up,sp }}$ & Upstream height set point \\
\hline $\mathrm{h}_{\text {weir }}$ & Height of the weir in the downstream volume of the RBF system \\
\hline$\eta_{\mathrm{TSS}}$ & TSS removal efficiency \\
\hline$\eta_{\mathrm{XHB}}$ & Removal efficiency of heterotrophic bacteria \\
\hline$\eta_{\mathrm{XI}}$ & Removal efficiency of inert particulate COD \\
\hline$\eta_{\mathrm{XS}}$ & Removal efficiency of slowly biodegradable COD \\
\hline$\vartheta$ & Inclination of the belt with respect to the horizontal direction \\
\hline $\mathrm{k}$ & Exponent for constant effect of cake resistance on filtered TSS \\
\hline $\mathrm{K}_{\mathrm{C}}$ & Control gain for water level control \\
\hline $\mathrm{K}_{\mathrm{C}, \mathrm{P}}$ & Control gain for polymer-addition control \\
\hline $\mathrm{K}_{\mathrm{g}}$ & Anti-windup gain for water level control \\
\hline $\mathrm{K}_{\mathrm{g}, \mathrm{P}}$ & Anti-windup gain for polymer-addition control \\
\hline $\mathrm{K}_{\text {poly }}$ & Conversion constant for polymer addition \\
\hline LHS & Latin Hypercube Sampling \\
\hline $\mathrm{L}_{\text {tot }}$ & Total length of the belt \\
\hline $\mathrm{m}$ & Angular coefficient for the effect of polymer on filtered TSS \\
\hline $\mathrm{m}_{1}$ & Angular coefficient of the mesh resistance-velocity relation \\
\hline & Mesh resistance when flux velocity is null \\
\hline $\mathrm{MC}$ & Monte Carlo \\
\hline $\mathrm{N}$ & Total number of discretization elements of the filter \\
\hline$\mu$ & Dynamic viscosity \\
\hline $\mathrm{PC}$ & Primary Clarifier \\
\hline
\end{tabular}




\begin{tabular}{|c|c|}
\hline pCOD & Particulate COD \\
\hline $\mathrm{pCOD}_{\text {bio }}$ & Biodegradable particulate COD \\
\hline $\mathrm{tCOD}$ & Total COD \\
\hline$[\text { polymer }]_{\text {in }}$ & Influent polymer concentration \\
\hline $\mathrm{Q}_{\text {eff }}$ & Effluent flow rate \\
\hline $\mathrm{Q}_{\text {filtered }}$ & Filtered flow rate \\
\hline$Q_{\text {in }}$ & Influent flow rate \\
\hline$Q_{\text {out }, A}$ & Sum of the flow rates leaving Volume A \\
\hline Qout,weir & Filtered flow rate leaving the RBF system \\
\hline $\mathrm{Q}_{\mathrm{of}}$ & Overflow flow rate \\
\hline $\mathrm{Q}_{\text {sludge }}$ & Primary sludge flow rate \\
\hline $\mathrm{R}^{2}$ & Coefficient of determination \\
\hline $\mathrm{RBF}$ & Rotating Belt Filter \\
\hline $\mathrm{R}_{\text {cake }}$ & Cake resistance \\
\hline $\mathrm{R}_{\text {mesh }}$ & Mesh resistance \\
\hline $\mathrm{S}_{\text {belt }}$ & Rotational Belt Speed \\
\hline $\mathrm{S}_{\text {belt,data }}$ & Data of belt speed collected while running RBF system \\
\hline $\mathrm{SF}_{\text {BeltSpeed }}$ & Belt speed scaling factor \\
\hline $\mathrm{SF}_{\mathrm{TSS} f i l t e r e d}$ & Filtered TSS scaling factor \\
\hline $\mathrm{SRC}$ & Standardized Regression Coefficient \\
\hline$t_{\mathrm{ct}}$ & Current time of column test \\
\hline$\tau_{\mathrm{I}}$ & Integrative time constant for water level control \\
\hline$\tau_{\mathrm{I}, \mathrm{P}}$ & Integrative time constant for polymer-addition control \\
\hline
\end{tabular}




\begin{tabular}{|c|c|}
\hline $\mathrm{TN}$ & Total Nitrogen \\
\hline TSS & Total Suspended Solids \\
\hline$[\mathrm{TSS}]_{\mathrm{effluent}}$ & Effluent TSS concentration \\
\hline$[\mathrm{TSS}]_{\text {filtered }}$ & Filtered TSS concentration \\
\hline$[\mathrm{TSS}]_{\text {filtered,data }}$ & Measured filtered TSS concentration \\
\hline$[\mathrm{TSS}]_{\text {in }}$ & Influent TSS concentration \\
\hline$[\mathrm{TSS}]_{\text {out,weir }}$ & Filtered TSS concentration leaving the RBF system \\
\hline [TSS] filtered & Filtered TSS concentration when the polymer is added \\
\hline$[\mathrm{TSS}]_{\text {sludge }}$ & Primary Sludge TSS concentration \\
\hline TSSscaling $_{A}$ & Scaling factor for A \\
\hline TSSscaling $_{\alpha}$ & Scaling factor for $\alpha$ \\
\hline TSSscaling $_{B}$ & Scaling factor for B \\
\hline TSSscaling $_{\beta}$ & Scaling factor for $\beta$ \\
\hline $\mathrm{U}$ & Generic Darcy's law velocity \\
\hline $\mathrm{U}_{\text {drop }}$ & Drop velocity of the height during a column test \\
\hline V & Cumulative filtered volume in a real RBF system \\
\hline $\mathrm{V}_{\mathrm{ct}}$ & Column test cumulative filtered volume \\
\hline $\mathrm{v}$ & Fluid velocity through the filter \\
\hline $\mathrm{V}_{\text {liq }}$ & Liquid volume \\
\hline $\mathrm{X}_{\mathrm{HB}}$ & Heterotrophic biomass \\
\hline$X_{I}$ & Inert particulate COD \\
\hline $\mathrm{X}_{\mathrm{S}}$ & Slowly biodegradable COD \\
\hline $\mathrm{w}_{\text {down }}$ & Width of the basis o \\
\hline
\end{tabular}




$\begin{array}{ll}\mathrm{w}_{\text {down,of }} & \text { Width of lower basis of overflow channel } \\ \mathrm{W} & \text { Width of RBF system } \\ \mathrm{w}_{\text {up }} & \text { Width of the basis of the RBF system upstream volume } \\ \mathrm{w}_{\text {up,of }} & \text { Width of upper basis of overflow channel } \\ \text { WWTP } & \text { Wastewater Treatment Plant }\end{array}$

\begin{abstract}
Rotating belt filters are a primary treatment technology currently used in municipal wastewater treatment plants as a high-rate alternative to primary clarifiers. Such systems are reported to efficiently remove particulates in the form of total suspended solids, achieving the highest removal efficiencies $(>60 \%)$ when polymer is added as pre-treatment step. In this paper, a new dynamic model describing the RBF performance is presented. The model includes the dynamic effects of influent flow rate and TSS concentration and can also describe the effects of polymer dosing on RBF performance. The validated model was used to perform a plant-wide impact assessment using the Benchmark Simulation Model n.2. For a TSS removal efficiency that is identical to primary clarifiers $(50 \%)$, rotating belt filters were found to only slightly decrease the aeration energy demand in the activated sludge unit $(-0.5 \%)$, while increasing methane production and slightly increasing effluent $\mathrm{TN}$ concentrations $(+1.5 \%$ and $+1.9 \%$, respectively). Furthermore, considerable savings in polymer costs could be attained using an advanced control strategy for polymer dosing, successfully tested in this work.
\end{abstract}

\title{
1. Introduction
}

Rotating belt filters (RBFs) are a high-rate primary treatment technology used to remove total suspended solids (TSS) from wastewaters by means of filtration by microsieving. In a typical RBF 
system, influent wastewater passes through a rotating filtering mesh with pores of a given size (typically in the 50-500 $\mu \mathrm{m}$ range) which promotes a controlled fractionation of TSS. In contrast to primary clarifiers (PCs) where solids are mainly removed as a function of their settling velocity, in RBF technologies separation occurs according to particle size. This is the main reason why RBFs are found to more efficiently remove fibers, such as cellulose originating from toilet paper, from influent wastewaters (Ruiken et al., 2013). As a slowly biodegradable COD fraction, cellulose is more conveniently treated in the sludge line (Chen et al., 2017; Ebeling et al., 2006; Paulsrud et al., 2014; Ruiken et al., 2013). Despite the considerable benefits of RBF systems as primary treatment, only few studies have been carried out to quantitatively assess the advantages and disadvantages resulting from the implementation of such a technology in municipal wastewater treatment plants (WWTPs) (Behera et al., 2018; Ruiken et al., 2013), thus preventing a wider adoption of such technologies in municipal treatment plants.

A first study, carried out by Behera et al. (2018), assessed the impact of RBF technologies on existing WWTPs by implementing an empirical steady-state model for RBFs into the Benchmark Simulation Model No2 (BSM2) by Jeppsson et al. (2007). The model-based impact assessment confirmed the expected advantages in terms of aeration energy demand savings and increased methane production, while pointing out an increased effluent nitrate concentration. However, the employed RBF model lacked descriptive capabilities of the system hydraulics, which impacts dynamic predictions of both TSS removal and system treatment capacity. Moreover, this model does not take into account RBF-specific operational factors, such as the submerged sieving area, which is proven to affect TSS removal (Sutton et al., 2008). Indeed, it should be mentioned that, in the full-scale technology, the submerged sieving area is proportionally and dynamically varied to control the upstream water level. Using simplified modelling approaches, the operational 
implication of a dynamic controller for the upstream water level cannot be investigated properly. A more realistic and dynamic description of the performance of RBF systems under a wider variety of influent dynamics and different operational strategies is therefore needed.

The main objective of this work is the development and validation of a dynamic model where the effect of flow rate and influent TSS variability are taken mechanistically into account. The newlydeveloped model is also extended to take into account the effect on hydraulic capacity and TSS removal associated with polymer addition. After extensive validation, the model was employed to perform a global impact assessment of RBF systems in full-scale WWTPs using the BSM2 platform to address potential advantages and drawbacks derived from the implementation of RBF technologies. Finally, an on-line control strategy for automatically regulating polymer addition as a function of RBF operational parameters was tested, and the plant-wide benefit quantified.

\section{System description}

A representation of a RBF is shown in Figure 1a, while Figure 1b illustrates a simplified schematic of the same system used for model development. Referring to Figure 1b, the RBF system modelled in this work can be split up into two main liquid volumes:

- Upstream volume (Volume A), where the influent wastewater is carried into the system, prior to filtration (on the left-hand side of the belt),

- Downstream volume (Volume B), from where the filtered wastewater leaves the system towards the biological treatment unit (on the right-hand side of the belt).

As the influent water is carried in, solids are retained on the surface of the inclined rotating filter, which screens particles larger than the pore size of the filtering mesh. The screened particles accumulate on the surface of the mesh, forming a cake layer which enables screening of particles 
smaller than the nominal mesh size. As the TSS accumulation on the belt proceeds, a higher water level is established in Volume A than in Volume B. This creates a difference in hydrostatic pressure across the filter, which is the driving force determining the flux of water through the filter, from Volume A to Volume B. Such force gets larger as the pressure difference increases. The continuously rotating motion of the belt allows for the accumulated solids to be transferred to the sludge treatment line after each filtration cycle via a cleaning mechanism (e.g. an air knife) located at the upper edge of the inclined filter. For fixed wastewater influent characteristics, low belt speeds lead to higher accumulation of TSS on the filter, since the removal of accumulated solids from the belt is less frequent, while high belt speeds lead to a lower accumulation as TSS are removed faster. In typical RBF systems, the belt speed is automatically regulated in order to keep the upstream water level $\left(h_{u p}\right)$ at a specific set point despite fluctuations in the influent TSS and flow rate. The upstream water level set point $\left(h_{u p, s p}\right)$ is typically chosen to be as high as possible in order to maximize the pressure difference between upstream and downstream, which in turn enables high TSS removal efficiencies.

Overflows typically occur when the influent TSS load to the system exceeds design capacity. Specifically, when an increased TSS load is carried into the system, accumulation of solids on the belt increases, resulting in a required increase of the belt speed to maintain the same water level. However, the belt speed typically has a minimum and a maximum value which vary according to the geometries of the machine used. If the belt speed reaches its maximum value and this is insufficient to handle the influent load, $h_{u p}$ will increase, potentially exceeding $h_{u p, \max }$. In this case, water flows into a collection channel located in Volume A. The water collected is then typically sent untreated to the mainstream biological treatment unit of the treatment plant, although in few applications it could be recycled back to the filter system to be treated. Overflow events reduce 
the TSS removal efficiency in the former case, as a portion of wastewater will not be treated. A reduction in removal performance can also occur when the influent TSS load is too low. In this case, the belt speed required to keep the water level at its set point is below the minimal value and, consequently, the water level decreases, slowing the filtration process and reducing the removal of TSS. The downstream water level $\left(h_{\text {down }}\right)$ is inherently controlled by the presence of a weir at the edge of the downstream compartment.

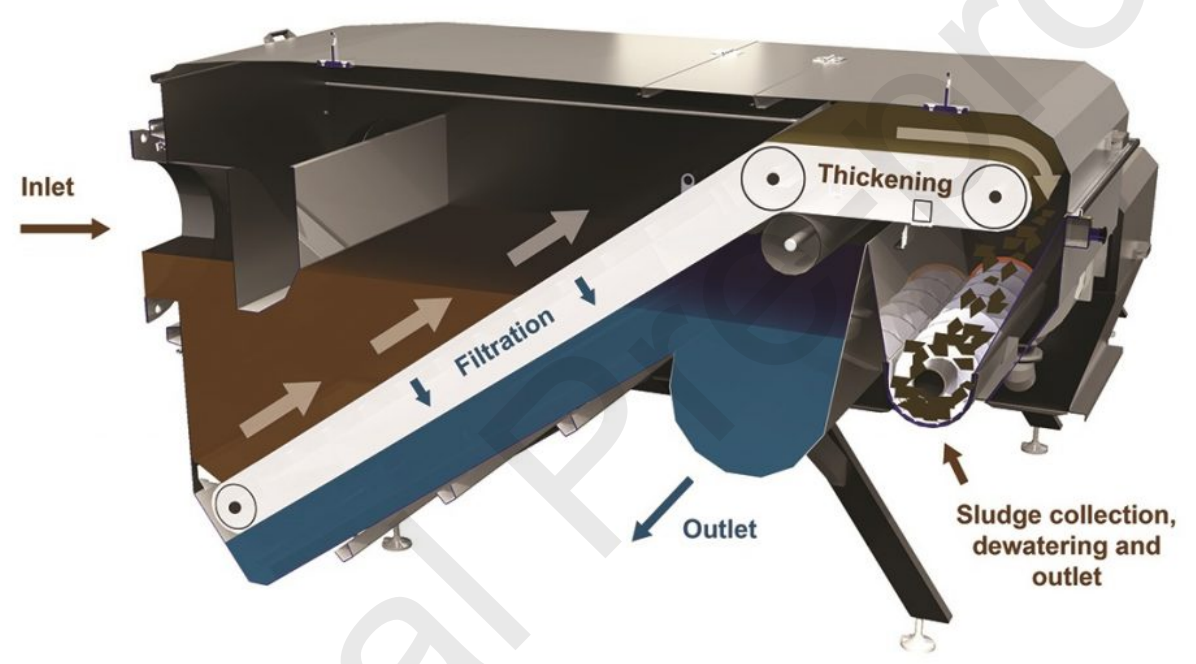

(a) 


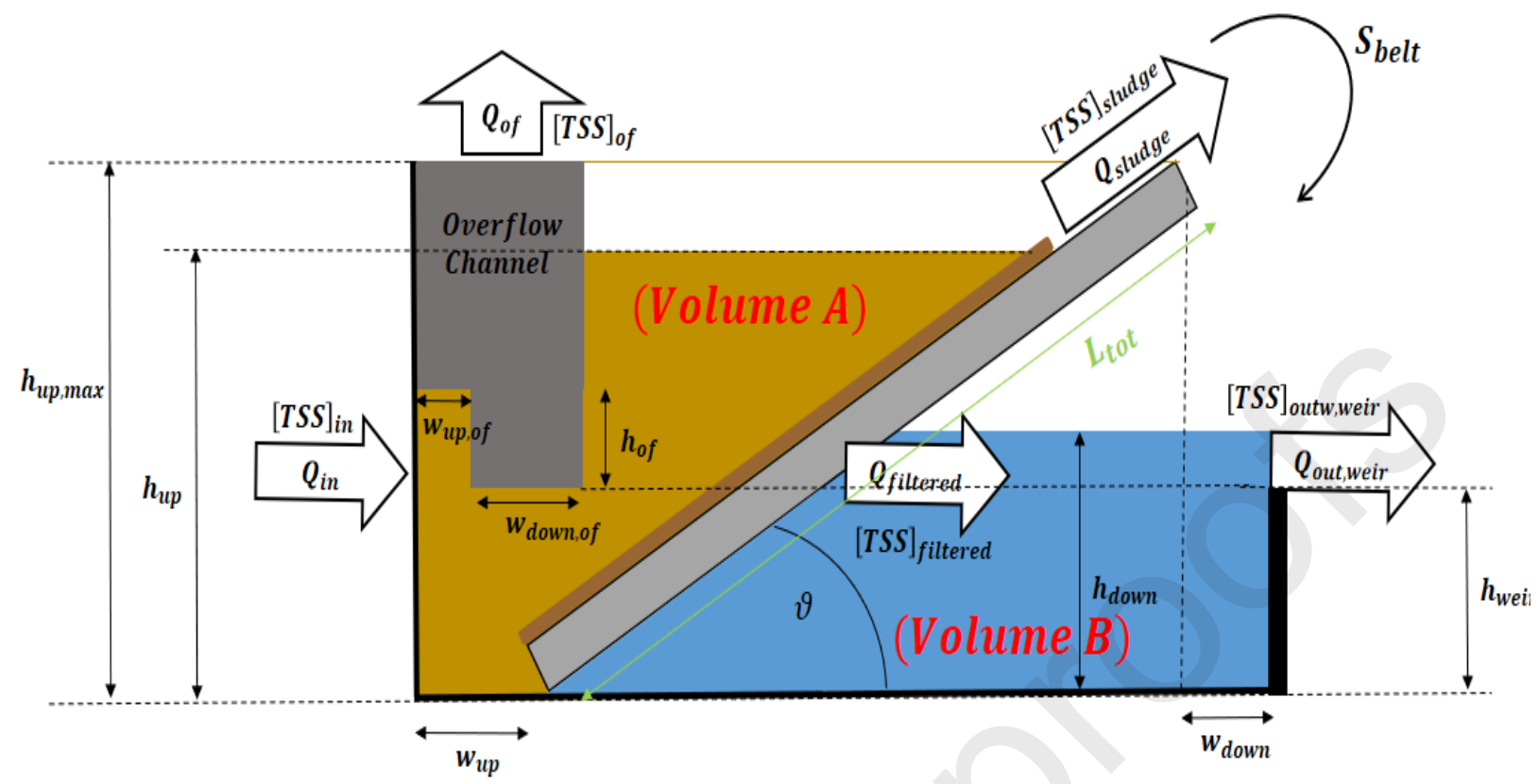

(b)

Figure 1: (a) Rendering of a commercial rotating belt filter, and (b) Schematic representation of a rotating belt filter used for modelling (all the symbols used are described in the "Nomenclature and Symbols" table).

\section{Model description}

The model is mainly composed of first-order ordinary differential equations describing the dynamic variations of upstream and downstream liquid heights and of algebraic equations for the flow rates and the TSS concentrations in the streams leaving both Volume A and Volume B (as indicated in Figure 1b). Influent flow rate and TSS concentration ( $Q_{i n}$ and $[T S S]_{i n}$, respectively) are input variables to the model, while TSS concentrations and flow rates in the effluent $\left([T S S]_{\text {eff }}\right.$ and $Q_{\text {eff }}$, respectively) and in the primary sludge ([TSS $]_{\text {sludge }}$ and $Q_{\text {sludge }}$, respectively) are the model outputs. 


\subsection{Identification of upstream and downstream water levels}

Referring to Figure $1 b$, the volumes of wastewater in the upstream and downstream compartments of the filter can be considered as distinct tanks communicating with each other through the filtered flow rate $\left(Q_{\text {filtered }}\right)$. Upstream and downstream liquid height variations with time can be derived from mass balances for both Volumes A and B, generically expressed in Eqn. (1).

$$
\frac{d V_{\text {liq }}(t)}{d t}=Q_{\text {in }}(t)-Q_{\text {out }}(t)
$$

By properly expressing the liquid volumes as functions of their respective geometry, the equations describing the temporal variations of water level in the upstream and downstream compartments of the filter system can be derived. Accordingly, the upstream liquid height variation as a function of time can be mathematically expressed as follows:

$$
\frac{d h_{u p}(t)}{d t}==\left(\begin{array}{cr}
\frac{Q_{\text {in }}(t)-Q_{\text {out }, A}(t)}{W \cdot\left(w_{u p}+h_{\text {up }}(t) / \tan (\vartheta)\right)} & \text { if } h_{\text {up }}(t)<h_{\text {wei }} \\
\frac{Q_{\text {in }}(t)-Q_{\text {out }, A}(t)}{W \cdot\left(w_{u p}+\frac{h_{u p}(t)}{\tan (\vartheta)}-w_{\text {down }, o f}\right)} & \text { if } h_{w e i r} \leq h_{u p}(t) \leq h_{\text {weir }}+h \\
\frac{Q_{\text {in }}(t)-Q_{\text {out }, A}(t)}{W \cdot\left(w_{u p}+\frac{h_{u p}(t)}{\tan (\vartheta)}-w_{\text {down }, o f}-w_{u p, o f}\right)} & \text { if } h_{u p}(t)>h_{\text {weir }}+h_{c}
\end{array}\right)
$$

where $Q_{o u t, A}$ is the sum of the flow rates leaving the upstream water volume, which consists of filtered flow rate $\left(Q_{\text {filtered }}\right)$, primary sludge flow rate $\left(Q_{\text {sludge }}\right)$, and overflow flow rate $\left(Q_{o f}\right)$, which is written as follows:

$$
Q_{\text {out }, A}(t)=Q_{\text {filtered }}(t)+Q_{\text {sludge }}(t)+Q_{o f}(t)
$$


Equation (2) had to be specified for three different cases in order to take into account the overflow channel, as represented in Figure $1 \mathrm{~b}$.

The mathematical expression, given below, for the downstream water level variation as a function of time is derived with a similar approach to the one followed for the upstream water level, where $Q_{\text {out,weir }}$ is the outlet flow rate of Volume B carried to the main stream biological line of the WWTP.

$$
\frac{d h_{\text {down }}(t)}{d t}=\frac{Q_{\text {filtered }}(t)-Q_{\text {out }, \text { weir }}(t)}{W \cdot\left(L_{\text {tot }} \cdot \cos (\vartheta)+\frac{h_{\text {down }}(t)}{\tan (\vartheta)}+w_{\text {down }}\right)}
$$

As previously mentioned, while $Q_{\text {in }}$ is an input variable to the model, the other flow rates $\left(Q_{\text {filtered }}\right.$, $Q_{\text {out,weir }}$ and $\left.Q_{o f}\right)$ are identified through algebraic equations which will be presented in the next sections.

\subsection{Identification of the filtered flow rate}

In the present model, the flow passed through the filter is identified according to the principles illustrated in DeGroot et al. (2016) and Sherratt et al. (2018a). Specifically, the approach is based on Darcy's law, according to which the velocity $(U)$ of a liquid through a porous media is directly proportional to the pressure drop $(\Delta P)$ and inversely proportional to the dynamic viscosity $(\mu)$ and the media resistance $(R)$, mathematically expressed as follows:

$$
U=\frac{\Delta P}{\mu \cdot R}
$$

In order to identify the fluid velocity through RBF systems, the filter domain must be spatially discretized. This is because the pressure drop along the filter varies from bottom to top, such that using a single lumped value of the pressure drop would be inaccurate. The pressure differential across the filter is the driving force of the filtration process, and therefore its accurate quantification 
along the filter is key to achieve proper model predictions. Besides the pressure drop, also the flow resistance of the medium is an important variable, which determines the hydrodynamic characteristics of the system as a function of the influent and operational parameters. In the case of RBF systems, the total flow resistance is a result of both the presence of the mesh filter and the layer of solids accumulated on it. As a result, the total resistance given in Eqn. (5) can be represented as the sum of cake and mesh resistances in series ( $R_{\text {cake }}$ and $R_{m e s h}$, respectively), where $R_{\text {cake }}$ is proportional to the amount of solids accumulated on the filter and $R_{m e s h}$ is a function of the mesh geometry and flow velocity (according to the Darcy-Forchheimer law). Once the flow velocity is known as a function of the position on the filter, the total filtered flow rate $\left(Q_{\text {filtered }}\right)$ is identified by summing up the local flow rates, each of which is the product of the local flow velocity and local filtration area $\left(A_{\text {filtr }, i}\right)$. Mathematically, $Q_{\text {filtered }}$ can be formulated according to Eqn. (6), where $N$ is the total number of elements along the filter into which the flow rate calculation is discretized.

$$
Q_{\text {filtered }}(t)=\sum_{i=1}^{N}\left(\frac{\Delta P_{i}(t)}{\mu \cdot\left(R_{\text {mesh }, i}(t)+R_{\text {cake }, i}(t)\right)} \cdot A_{\text {filtr }, i}\right)
$$

In Eqn. (6), the pressure drop will be a function of the water levels in the upstream and downstream compartments, identified through Eqns (2-3). The dynamic viscosity and the filtration area are easily identified by the fluid properties and the geometry of the system. The mesh and cake resistances are treated not as mechanistic but as empirical variables that must be determined by experimentation through correlation with other model variables. An extensive explanation for the derivation of mathematical expressions of these two model variables is presented in the next section. 


\section{Mathematical expressions for mesh and cake resistances}

The mathematical expression for cake resistance is identified based on experimental results obtained from gravity drainage column tests, which allow for the measurement of total resistance as a function of the cumulative filtrate volume. The column test procedure has been described previously by DeGroot et al. (DeGroot et al., 2015) and Sherratt et al. (Sherratt et al., 2018a) and is here briefly reported to ease the understanding of the mathematical structure of the model. Column test experiments consist of a vertical column of wastewater and a mesh filter with a known pore size, separated by a valve. Once the column is filled, the valve is completely opened, thus allowing the water to pass through the filter. An analog sensor continuously measures the water level as a function of time. The reason for using column tests to derive the expression for cake resistance in real RBF systems is that the filtration process occurs, similarly to real RBF systems, according to Darcy's law of filtration.

A typical plot of the water level as a function of time obtained during a column test is presented in Figure 2. 


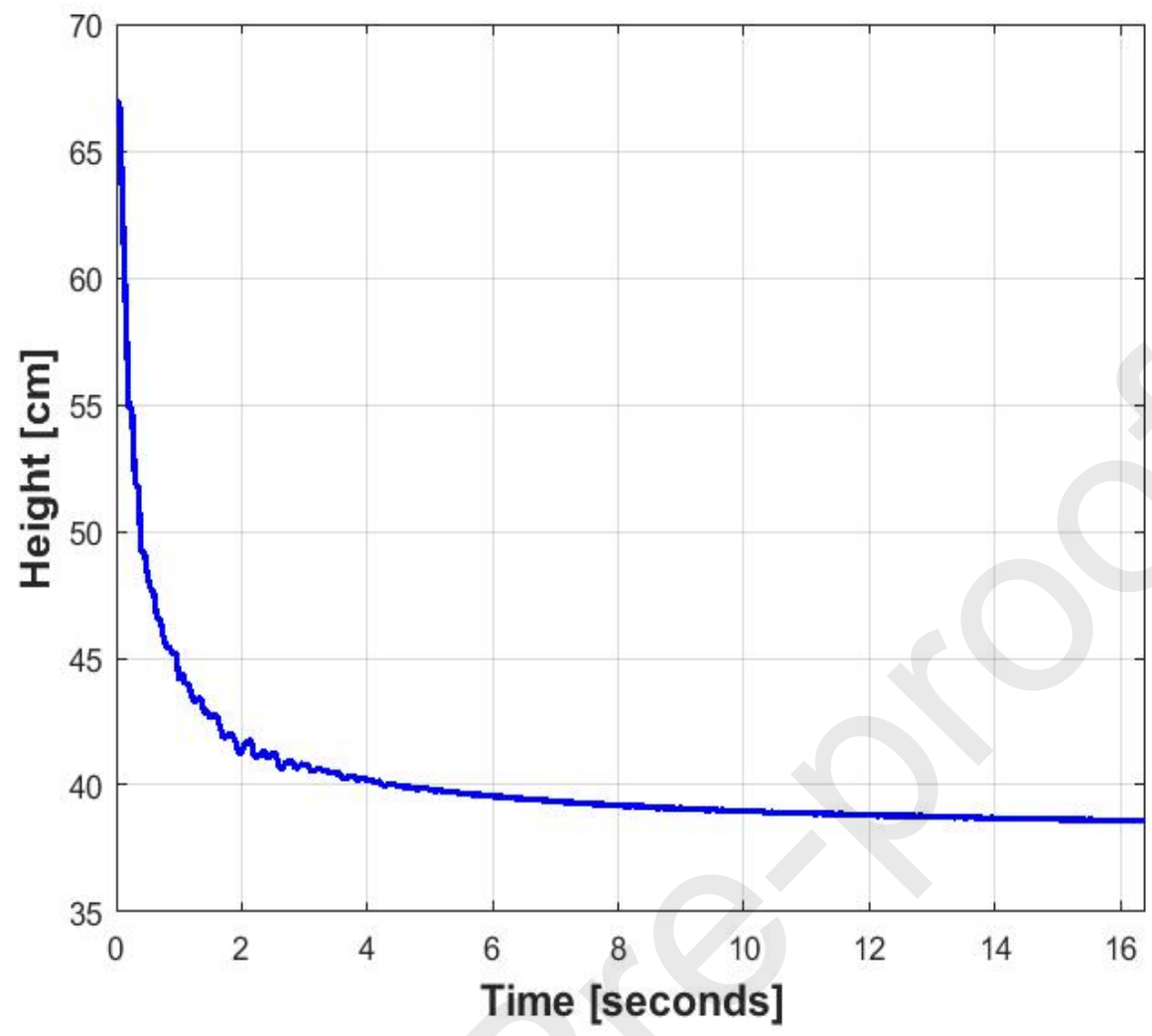

Figure 2: Typical height drop inside the column during experiments.

The double exponential of Eqn. (7) has been identified as a suitable mathematical formulation that is able to describe the measured height variation as a function of time in a column test.

$$
h\left(t_{c t}\right)=A \cdot e^{-\alpha \cdot t_{c t}}+B \cdot e^{-\beta \cdot t_{c t}}
$$

In Eqn. (7), $A$ represents the liquid height associated with the initial fast drop in water level, which occurs when the filter has accumulated virtually no solids (i.e. the mesh sieving process), while $B$ represents the liquid height associated with the slower drop in height, which occurs when the solid accumulation is significant and the filtration rate is drastically reduced (i.e. the cake filtration process). The parameters $\alpha$ and $\beta$ are indicators of the filtration rates associated with the mesh sieving and cake filtration processes, respectively. The parameter $t_{c t}$ is the elapsed time from the beginning of the column test. 
By differentiating Eqn. (7) with respect to time, the flow velocity can be found to be as follows:

$$
U_{d r o p}\left(t_{c t}\right)=-\frac{d h\left(t_{c t}\right)}{d t_{c t}}=A \cdot \alpha \cdot e^{-\alpha \cdot t_{c t}}+B \cdot \beta \cdot e^{-\beta \cdot t_{c t}}
$$

To determine the mesh resistance, steady-state experiments have been conducted by Sherratt et al., (2018b) using a pumped flow through a horizontal pipe containing a mesh filter, with pressure transducers on either side. Conducting these tests over a range of flow rates showed that the mesh resistance increases linearly with the bulk velocity in the pipe, as expressed by the following equation:

$$
R_{\text {mesh }}(t)=m_{1} \cdot U_{d r o p}(t)+m_{2}
$$

The cake resistance expression as a function of $A, B, \alpha$ and $\beta$ (see Eqn. (10)) can be obtained by rearranging Eqn. (5) and replacing $R_{\text {mesh }}$ with the expression in Eqn. (9).

$$
R_{\text {cake }}\left(t_{c t}\right)=\rho \cdot g \cdot \frac{A \cdot e^{-\alpha \cdot t_{c t}}+B \cdot e^{-\beta \cdot t_{c t}}}{\left(\mu \cdot\left(A \cdot \alpha \cdot e^{-\alpha \cdot t_{c t}}+B \cdot \beta \cdot e^{-\beta \cdot t_{c t}}\right)\right)}-m_{1} \cdot\left(A \cdot \alpha \cdot e^{-\alpha \cdot t_{c t}}+B \cdot \beta \cdot e^{-\beta \cdot t_{c t}}\right)-m_{2}
$$

Since at the beginning of the filtration process no solid is accumulated on the surface of the filter, the value of $m_{l}$ in Eqn. (10) is identified for the real RBF case by assuming that the cake resistance at time $t$ equal to zero is null. All the other parameters will be calibrated to fit real RBF system dynamics, as presented in Section 4.

The cumulative filtered volume of the column test $\left(V_{c t}\right)$, which is the cumulative amount of water passed through the filter of the column during a test, can be mathematically expressed per unit of filtration area by subtracting the initial water height from the current height inside the column, as expressed in Eqn. (11).

$$
V_{c t}\left(t_{c t}\right)=h_{0}-h\left(t_{c t}\right)=A \cdot\left(1-e^{-\alpha \cdot t_{c t}}\right)+B \cdot\left(1-e^{-\beta \cdot t_{c t}}\right)
$$


A typical relationship between cumulative filtered volume and cake resistance for a wastewater with a known concentration of TSS can now be identified using Eqns. (10-11). Figure 3 shows an example of such a relationship.

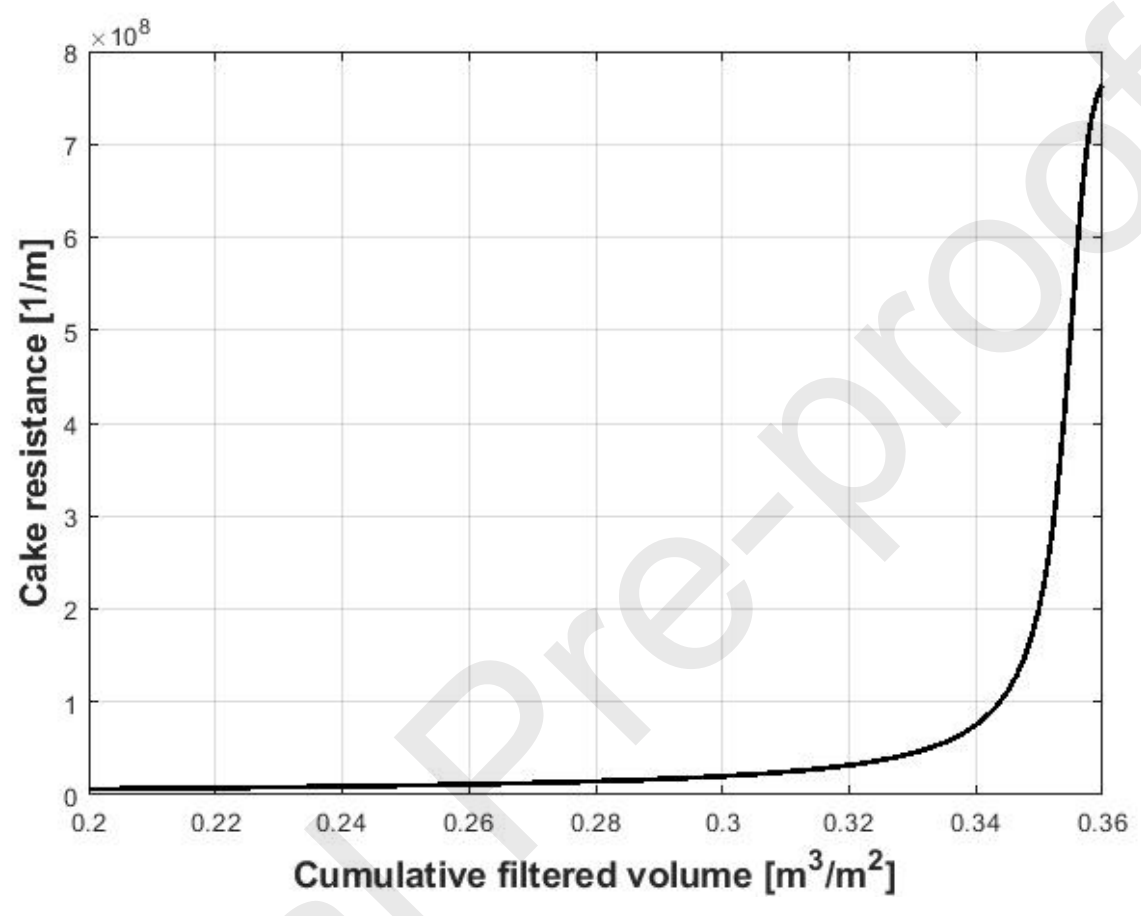

Figure 3: Example of the relationship between cumulative filtered volume and cake resistance for a given concentration of TSS in the water.

As can be seen, the cake resistance is proportional to the cumulative filtered volume. This is expected since, for a given influent wastewater with a fixed concentration of TSS, the more water has passed through the filter (i.e. the higher the cumulative filtered volume), the more solids have been accumulated on the filter, and the higher the cake resistance will be. 
In the dynamic model for RBF systems, this $R_{c a k e}{ }^{-} V_{c t}$ relationship is exploited to identify the cake resistance for an element of the belt on the basis of its current cumulative filtered volume by interpolation.

As mentioned before, the $R_{\text {cake }}-V_{c t}$ relationship is specific to a given wastewater TSS concentration. To incorporate the effect of influent TSS concentration variations in the hydrodynamic model, this relationship needs to be adjusted for different influent TSS concentrations. To this end, column tests with wastewaters of different TSS contents and with clean water were performed and the parameters $A, B, \alpha$ and $\beta$ were estimated for each of them. Figure 4 shows the values of these four parameters as functions of the TSS concentration. By fitting the mathematical formulas expressed in Eqn. (12), the values of $A, B, \alpha$ and $\beta$ as functions of the influent TSS concentration could be identified. With regards to the expression for $\beta$, although a simpler linear trend could be identified as fitting the three measurement points, an exponential equation was chosen in order to avoid negative values of the parameter in case of high TSS concentrations. Given the physical meaning of this parameter, negative values would not be reasonable.

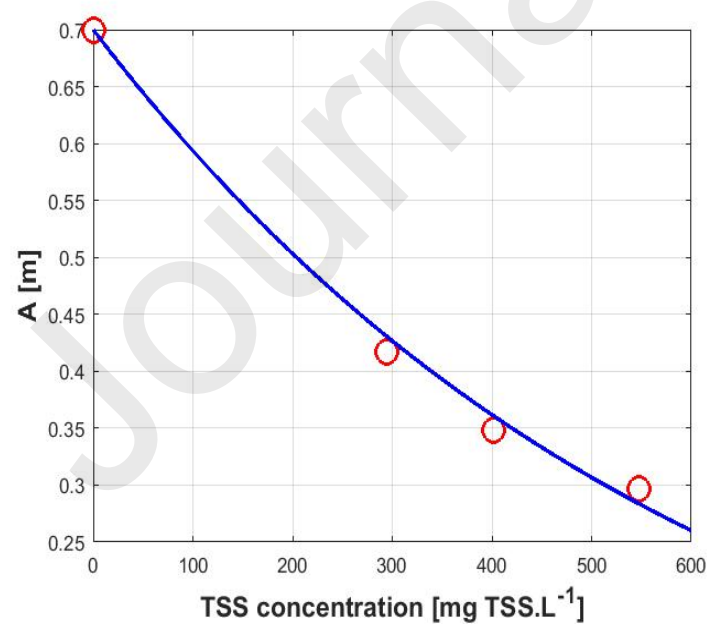

(a)

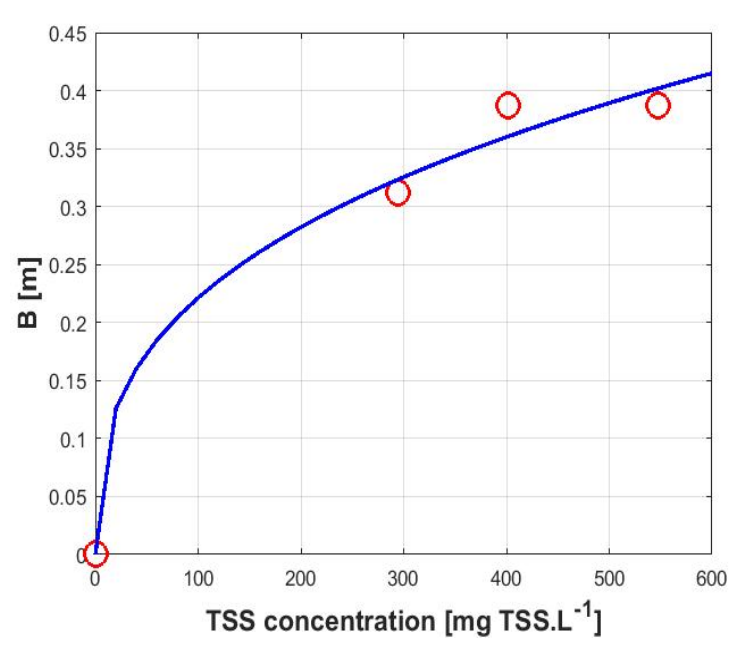

(b) 


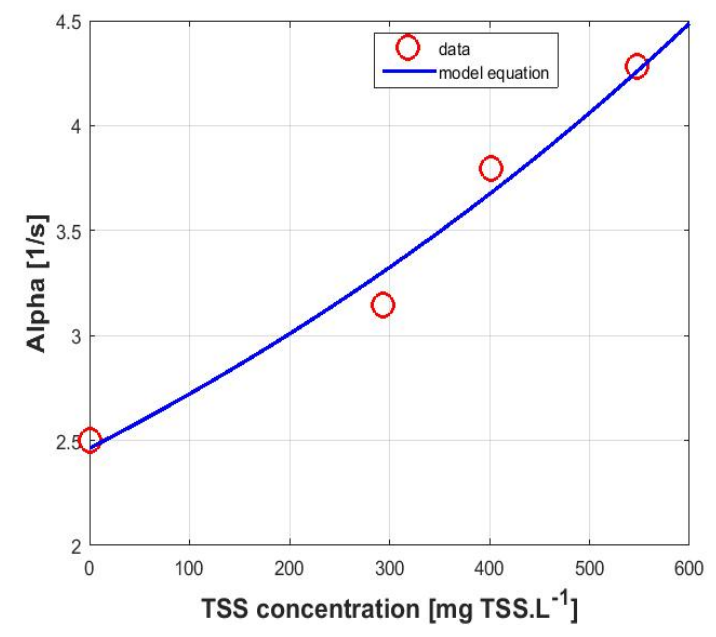

(c)

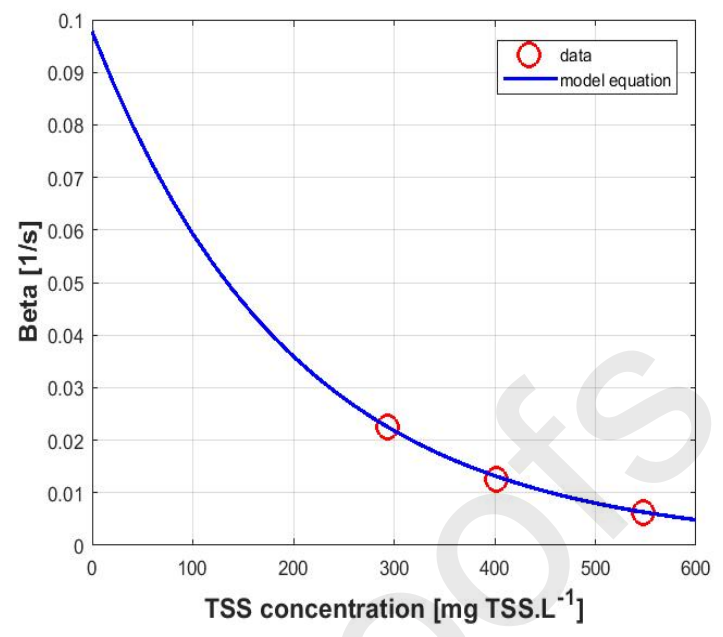

(d)

Figure 4: Relationships between $A, B, \alpha$ and $\beta$ and the influent TSS concentration identified during column tests (note that when clean water was used, i.e. TSS equal to 0 , the value of $B$ was zero, meaning that $\beta$ could not be estimated).

$$
\left\{\begin{array}{c}
A=A_{\text {ref }} \cdot e^{- \text {TSSscaling }_{A} \cdot \text { TSS }_{i n}} \\
B=B_{\text {ref }} \cdot \text { TSS }_{\text {in }}^{\text {TSSscaling }} B \\
\alpha=\alpha_{r e f} \cdot e^{\text {TSScaling }_{\alpha} \cdot T S S_{i n}} \\
\beta=\beta_{\text {ref }} \cdot e^{- \text {TSSscaling }_{\beta} \cdot \text { TSS }_{i n}}
\end{array}\right.
$$

In the dynamic model for RBF systems, knowing the influent TSS concentration, the values for $A$, $B, \alpha$ and $\beta$ are first identified on the basis of Eqn. (12). This enables identifying the correct relationship between cumulative filtered volume and cake resistance.

Secondly, the cumulative filtered volume of the bottom element of the discretized filter $\left(V_{0}\right)$ is initialized to zero assuming that the filter starts with no accumulated solids. Then, the cumulative filtered volume $\left(V_{i}\right)$ at each subsequent element along the filter is calculated according to Eqn. (13). As presented, the incremental filtration volume that is added at each element is a function of 
the velocity through the filter $\left(v_{i}\right)$, which is in turn proportional to the pressure difference across the filter and the filter resistance, and the ratio between the length of the element $\left(\Delta x_{i}\right)$ and the belt speed $\left(S_{b e l t}\right)$, which represents the time taken for the filter to pass through the distance $\Delta x_{i}$.

$$
V_{i}(t)=V_{i-1}(t)+\frac{v_{i}(t) \cdot \Delta x_{i}}{S_{b e l t}}
$$

Once the filtered volume is known, the cake resistance of the element can be identified by interpolating the previously identified relationship between $V_{c t}$ and $R_{c a k e}$.

\subsection{Determination of filtered TSS concentration}

It is important to point out that the concentration of filtered TSS described in this section does not always coincide with the effluent TSS concentration of the system. There are instances where the influent TSS load to the system is so high that overflow will occur. If the portion of influent in the overflow is carried directly to the mainstream line treatment instead of being recycled on top of the RBF system (as it is in most cases), the effluent TSS concentration will be higher than the TSS concentration in the downstream section of the RBF (namely the filtered TSS concentration). The filtered TSS concentration is simply the concentration of TSS in the influent stream to Volume B of Figure 1b, which is formulated as follows:

$$
[T S S]_{\text {filtered }}(t)=[T S S]_{\text {in }}(t) \cdot e^{-k \cdot[T S S]_{i n}(t)} \cdot e^{-\gamma \cdot V_{N}(t)}
$$

As can be observed, the model variable is found by multiplying the influent TSS concentration $[\mathrm{TSS}]_{\text {in }}$ with two exponential functions: 
(a) $e^{-k \cdot[T S S]_{i n}(t)}$, according to which the filtered TSS concentration decreases as a result of an increased sieving efficiency associated with the presence of larger particles at higher influent TSS. This is likely due to the higher relative abundance of larger particles when larger solids are remobilized in the sewer system by a higher scouring velocity

(b) $e^{-\gamma \cdot V_{N}(t)}$, according to which the filtered TSS concentration is decreased with increasing cumulative filtered volume, which is in turn proportional to the current cake resistance. This phenomenon occurs due to accumulation of solids on the belt which enables, as explained in Section 2 and Figure 3, finer solid particles to be progressively screened out (Note: the cumulative filtered volume $\left(V_{N}\right)$ here used is the one calculated at the upper edge of the filter, which is the sum of the filtered volumes of all the elements of the belt into which the calculation was discretized).

Compared to the formulation proposed by Behera et al. (Behera et al., 2018), presented in the following equation,

$$
[T S S]_{\text {filtered }}^{*}=K_{1}^{*} \cdot[T S S]_{\text {in }} \cdot e^{-k_{2}^{*} \cdot[T S S]_{\text {in }}}
$$

the novelty introduced by the present formulation is that the effect of influent TSS concentration on the filtered TSS is no longer considered to be constant, but is allowed to vary according to current operational conditions of the RBF system such as water level and belt speed, which are variables upon which the cumulative filtered volume, included with the second exponential of Eqn. (14), depends. For example, for the same influent conditions, a higher upstream water level will lead to a decrease in the filtered TSS concentration, as a result of the larger filtered volume. 


\subsection{Determination of outlet flow rates and TSS concentrations}

To close material and flow balances, additional flow rates and TSS concentrations must be determined. The following are the quantities and mathematical descriptions required by the newly developed RBF model for various output streams of a RBF system:

- Overflow flow rate $\left(Q_{o f}\right)$ and TSS concentration $\left([\mathrm{TSS}]_{o f}\right)$,

- Effluent flow rate $\left(Q_{\text {eff }}\right)$ and TSS concentration $\left([\mathrm{TSS}]_{\text {eff }}\right)$, and

- Sludge flow rate $\left(Q_{\text {sludge }}\right)$ and TSS concentration $\left([\mathrm{TSS}]_{\text {sludge }}\right)$.

\section{Overflow flow rate and TSS concentration}

With regard to the case when the upstream height exceeds the maximum level, a formula describing the flow rate over rectangular weirs according to Hager (2010) is used to calculate the overflow flow rate, as presented in Eqn. (16).

$$
Q_{o f}(t)=\left\{\begin{array}{lr}
0 & \text { if } h_{u p}(t)<h_{u p, \max } \\
\frac{2}{3} \cdot C_{d}^{o f} \cdot W \cdot \sqrt{2 \cdot g} \cdot\left(h_{u p}(t)-h_{u p, \max }\right)^{3 / 2} & \text { if } h_{u p}(t) \geq h_{u p, \max }
\end{array}\right.
$$

As can be seen, the overflow flow rate is null when the upstream water height $\left(h_{u p}\right)$ is below the height of the maximum upstream level $\left(h_{u p, \max }\right)$, while it is proportional to the difference between $h_{u p}$ and $h_{u p, \max }$ in the other case. The discharge coefficient $\left(C_{d}^{o f}\right)$ can be tuned during the calibration in case measurements of heights above the maximum level are available, as will be shown in Section 4.

Given the small dimensions of the upstream volume, it can be assumed that the TSS concentration is uniform within that region. Therefore, the concentration of TSS in the overflow can be approximated to be equal to the one in the influent to the system, as expressed in Eqn. (17).

$$
[T S S]_{o f}(t)=[T S S]_{\text {in }}(t)
$$




\section{Effluent flow rate and TSS concentration}

The effluent flow rate is given by the sum of the overflow flow rate (in case the latter is not recycled back to the system) and the flow rate leaving Volume B ( $\left.Q_{\text {out,weir }}\right)$, as expressed by Eqn. (18).

$$
Q_{e f f}(t)=Q_{o f}(t)+Q_{o u t, w e i r}(t)
$$

$Q_{o u t, w e i r}$ is calculated similarly to the case of the overflow flow rate in Eqn. (16) according to Eqn.

(19), where the discharge coefficient $C_{d}^{\text {out,weir }}$ is attributed the same value as $C_{d}^{o f}$, given the similar geometries of the two weirs. This value could be calibrated in case measurements of both $Q_{\text {filtered }}$ and $h_{\text {down }}$ were available, or a measurement of different flow rates over the weir.

$$
Q_{\text {out }, \text { weir }}(t)=\left\{\begin{array}{cc}
0 & \text { if } h_{\text {down }}(t)<h_{\text {weir }} \\
\frac{2}{3} \cdot C_{d}^{\text {out,weir }} \cdot W \cdot \sqrt{2 \cdot g} \cdot\left(h_{\text {down }}(t)-h_{\text {weir }}\right)^{3 / 2} & \text { if } h_{\text {down }}(t) \geq h_{\text {weir }}
\end{array}\right.
$$

In the case where the overflow flow rate is not recycled back into the system, the TSS concentration in the effluent is given by the combination of the TSS flux in the stream leaving Volume B and the TSS flux of the overflow, as expressed in the following equation:

$$
[T S S]_{e f f}(t)=\frac{[T S S]_{o f}(t) \cdot Q_{o f}(t)+[T S S]_{\text {out weir }}(t) \cdot Q_{o u t, w e i r}(t)}{Q_{e f f}(t)}
$$

where the concentration of TSS in the stream leaving Volume B ([TSS $\left.]_{\text {out, weir }}\right)$ is equal to the concentration of filtered TSS, given the small dimensions of the downstream volume, as written in Eqn. (21).

$$
[T S S]_{\text {out }, \text { weir }}(t)=[T S S]_{\text {filtered }}(t)
$$

Primary sludge flow rate and TSS concentration 
Regarding the TSS concentration in the primary sludge, an empirical relation is used in this model. This is presented in Eqn. (22) and obtained by interpolating pilot data collected during operation of a pilot RBF unit (Salsnes Filter SF1000) shown in Figure 5.

$$
[T S S]_{\text {sludge }}(t)=a_{\text {sludge }} \cdot f(t)^{-b_{\text {sludge }}} \cdot \rho_{\text {slduge }}
$$

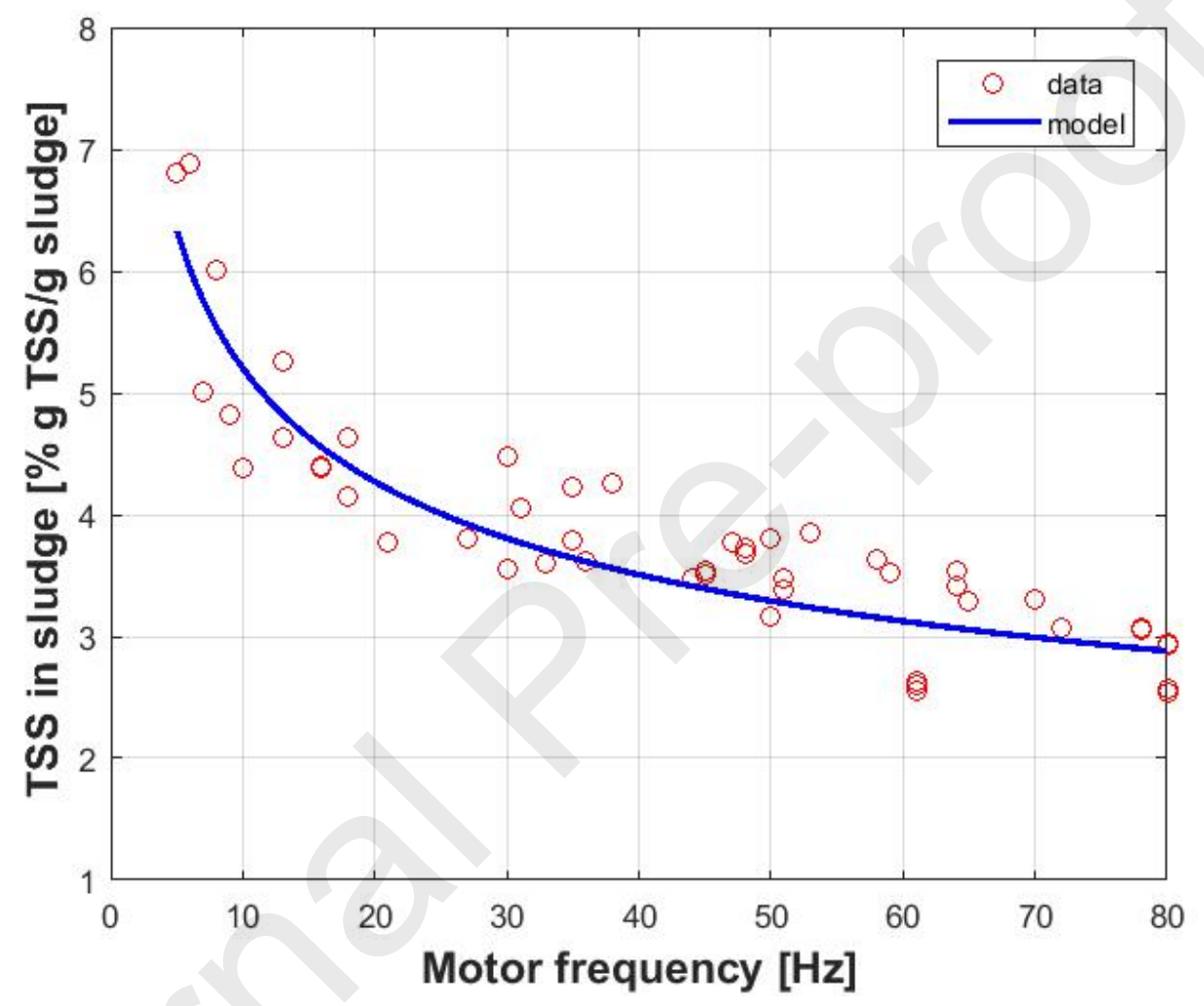

Figure 5: Empirical relation between TSS concentration in sludge and motor frequency.

In Eqn. (22) $f$ is the rotation frequency of the motor that controls the rotation of the belt, which has units of $[\mathrm{Hz}]$. The parameters $a_{\text {sludge }}$ and $b_{\text {sludge }}$ are estimated to be 0.1 and 0.284 , respectively, based on the model fit shown in Fig. 5. 
According to the expression identified in Eqn. (22), the TSS concentration in the sludge decreases with the belt speed. Referring to Figure 1a, this behaviour is expected since low belt speeds allow more time for the sludge to thicken in the upper part of the filter, which in turn increases the concentration of TSS in the sludge.

Finally, sludge flow rate is identified from the TSS mass balance around Volume A, which results in the following expression:

$$
Q_{\text {sludge }}(t)=\frac{\operatorname{TSS}_{\text {in }}(t) \cdot Q_{\text {in }}(t)-Q_{\text {filtered }}(t) \cdot T S S_{\text {filtered }}(t)-Q_{\text {of }}(t) \cdot T S S_{\text {of }}(t)}{T S S_{\text {sludge }}(t)}
$$

\subsection{Modelling the polymer addition effect}

The polymer effect is included in the model through appropriate modifications of the equations presented previously. Specifically, the equations for the filtered TSS concentration and for the relationship between cumulative filtered volume and cake resistance are updated.

\section{Modelling polymer influence on TSS removal efficiency}

The polymer effect is modelled as an additional amount of solids accumulated on the belt in virtue of the increased nominal particle sizes due to flocculation. For this reason, the filtered TSS concentration has to be lower when polymer is added. As a first approach, the effect of cake resistance on filtered TSS is hypothesized to increase linearly with the concentration of polymer in the influent to the system ([polymer $\left.]_{i n}\right)$, which means that the first exponential of Eqn. (14) is corrected with a linear correlation including polymer concentration, as shown in Eqn. (24).

$$
[T S S]_{\text {filtered }}^{\text {poly }}(t)=[T S S]_{\text {in }}(t) \cdot e^{-\left(k+m \cdot[\text { polymer }]_{\text {in }}(t)\right) \cdot[T S S]_{\text {in }}(t)} \cdot e^{-\gamma \cdot V_{N}(t)}
$$


Modelling polymer influence on relationship between cake resistance and cumulative filtered volume

The effect of polymer addition on the cake resistance is included by adding a virtual TSS concentration $\left(\right.$ TSS $\left._{i n}^{\text {poly }}\right)$ to the real influent TSS concentration used to scale the parameters defining the previously described $R_{\text {cake }} V_{c t}$ relationship (namely $A, B, \alpha$ and $\beta$ of Eqn. (12)) as follows:

$$
[T S S]_{i n}^{\text {new }}(t)=[T S S]_{\text {in }}(t)+[T S S]_{\text {in }}^{\text {poly }}(t)
$$

In Eqn. (25) $[T S S]_{\text {in }}$ is the actual concentration of TSS in the influent to the system while $[\text { TSS }]_{\text {in }}^{\text {new }}$ is the concentration of TSS used as input to Eqn. (12).

The procedure used to quantify [TSS $]_{i n}^{\text {poly }}$ is presented as follows. Let us consider two quantities: the concentration of TSS accumulated on the belt in the case of polymer addition ([TSS $]_{a c c}^{p o l y}$ ), which is due to both the presence of influent TSS and the polymer, and the one of a parallel hypothetical case when the polymer is not added $\left([T S S]_{a c c}\right)$. By taking the difference between these two, the additional amount of solids accumulated on the belt attributed to polymer injection ([ $\Delta T S$ $S]_{a c c}^{\text {poly }}$ is known, as presented in Eqn. (26).

$$
[\Delta T S]_{a c c}^{p o l y}(t)=[T S S]_{a c c}^{p o l y}(t)-[T S S]_{a c c}(t)
$$

In Eqn. (26) $[T S S]_{a c c}^{p o l y}$ and $[T S S]_{a c c}$ represent the difference between influent TSS concentration and their respective filtered TSS concentration (see Eqn. (27)) with and without polymer addition, respectively.

$$
\left\{\begin{array}{l}
{[T S S]_{a c c}^{\text {poly }}(t)=[T S S]_{\text {in }}(t)-[T S S]_{\text {filtered }}^{\text {poly }}(t)} \\
{[T S S]_{\text {acc }}(t)=[T S S]_{\text {in }}(t)-[T S S]_{\text {filtered }}(t)}
\end{array}\right.
$$


To convert the amount of solids additionally accumulated on the belt due to polymer addition, calculated according to Eqn. (26), to the amount of TSS virtually added to the system as additional influent TSS by the introduction of polymer, a coefficient $\left(K_{\text {poly }}\right)$ is used, as expressed in Eqn. (28).

$$
T S S_{\text {in }}^{\text {poly }}(t)=K_{\text {poly }} \cdot \Delta T S S_{\text {acc,poly }}(t)
$$

$K_{\text {poly }}$ is unknown and its value will be found during the calibration of the model.

\section{Model calibration and validation}

The model described in Section 3 is calibrated using a pilot scale data set. The calibrated model is then tested under different scenario for model validation.

The data used during both calibration and validation were collected by operating a RBF system (commercialized as the Salsnes Filter model SF2000) with a nominal mesh size of $350 \mu \mathrm{m}$. The system was operated in automatic control mode, where the upstream height had a set point of 0.44 meters (measured from the bottom of the upstream volume). The system was located at the Greenway Wastewater Treatment Center in London (Canada) where the primary influent municipal wastewater was pumped into the RBF inlet. Data were recorded with a sampling interval of 50 seconds.

In order to replicate the operation of the actual system, both calibration and validation are carried out on the previously-described RBF dynamic model implemented in MATLAB/Simulink with a Proportional-Integral control loop for upstream height, as shown in Figure 6. The initial guesses for the control parameter values are determined according to the Internal Model Control technique by Rivera et al. (1986) using initial guess model parameters. The values were later adjusted to the ones reported in Table 1 in order to optimize the control response. 
The explicit ordinary differential equation solver Ode15s is used to integrate the governing equations in time. To assess the hydrodynamic descriptive capability of the model, belt speed control response obtained from model simulation is compared against the one recorded during plant operation while the filtered TSS concentrations predicted and measured are compared with each other to assess the TSS removal performance.

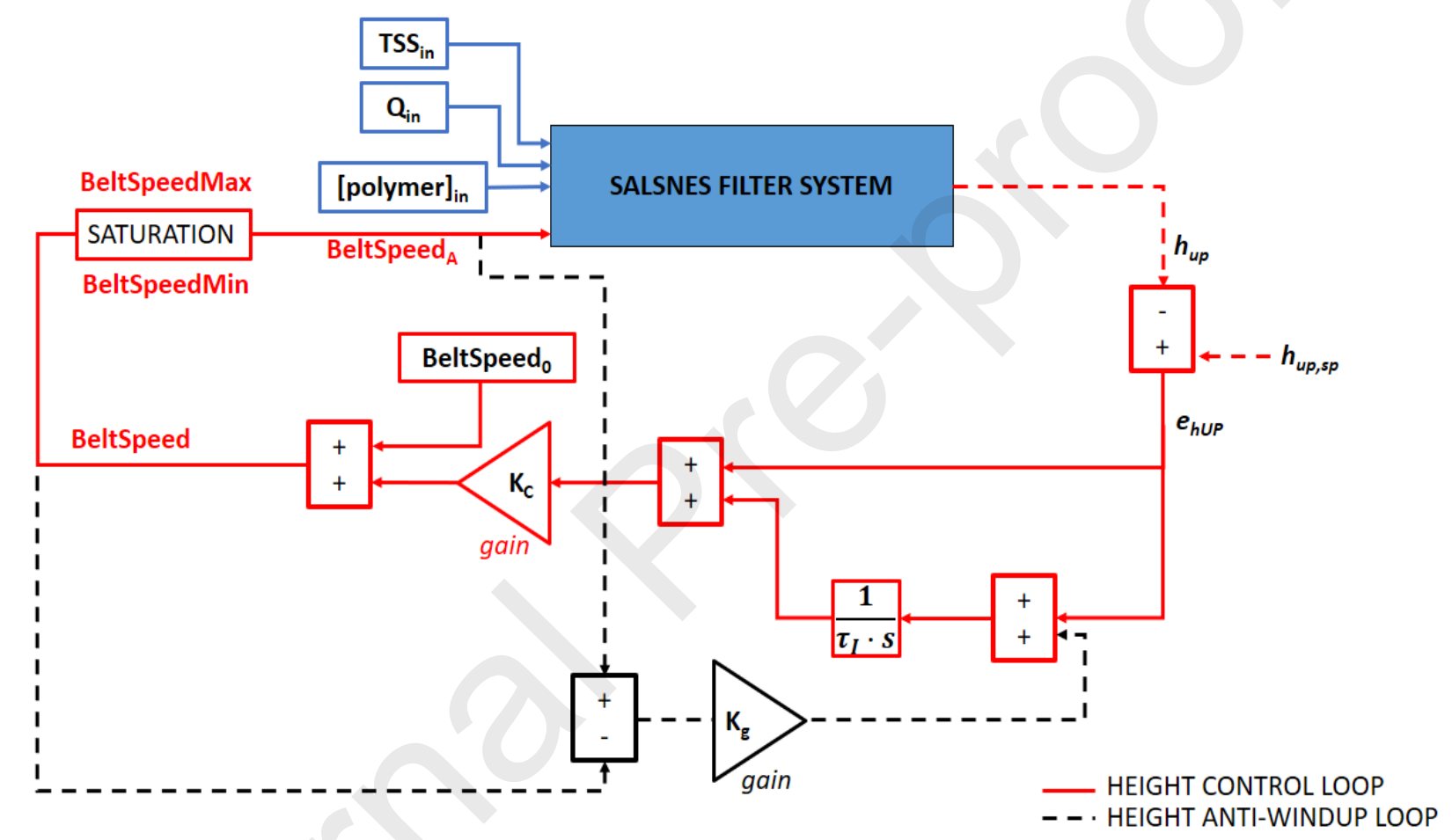

Figure 6: RBF simulation model layout used during calibration and validation. 
Table 1: Parameter values for implementation of a control strategy for upstream height in the RBF simulation model.

\begin{tabular}{|c|c|c|c|}
\hline Parameter & Symbol & Value & Unit of measurement \\
\hline Proportional Gain & $\mathrm{K}_{\mathrm{C}}$ & -109 & {$[(\mathrm{~cm} / \mathrm{s}) / \mathrm{m}]$} \\
\hline Integral time constant & $\tau_{\mathrm{I}}$ & 0.0382 & {$[\mathrm{~min}]$} \\
\hline Anti-windup gain & $\mathrm{K}_{\mathrm{g}}$ & -0.003 & {$[\mathrm{~m} /(\mathrm{cm} / \mathrm{s})]$} \\
\hline Nominal belt speed & BeltSpeed $_{0}$ & 15.5 & {$[\mathrm{~cm} / \mathrm{s}]$} \\
\hline Minimum belt speed & BeltSpeedMin & 1.5 & {$[\mathrm{~cm} / \mathrm{s}]$} \\
\hline Maximum belt speed & BeltSpeedMax & 24.7 & {$[\mathrm{~cm} / \mathrm{s}]$} \\
\hline Upstream height set point & $\mathrm{h}_{\text {up,sp }}$ & 0.44 & {$[\mathrm{~m}]$} \\
\hline
\end{tabular}

\subsection{Model calibration}

During calibration, the parameters describing the cake resistance with and without polymer addition (namely $A_{r e f}, B_{r e f}, \alpha_{r e f}, \beta_{r e f}, T_{S S S c a l i n g}, T_{S S s c a l i n g}, T S S s c a l i n g_{\alpha}, T S S s c a l i n g_{\beta}, m_{2}$ and $K_{\text {poly }}$ of Eqns. (10), (11), (12), and (28)) are optimized, along with those defining the filtered TSS concentration (namely $k, m$, and $\gamma$ of Eqn. (24)). Figure 7 shows the data used as inputs to the model collected during plant operation. Time 0 represents the beginning of the monitoring period, which is approximately around 9 a.m. Two TSS influent peaks to the WWTP occurred around midday and in the early afternoon. The influent flow rate is controlled to a set point of 10 Liters per second while a high molecular weight cationic polymer is added in a stepwise manner. 


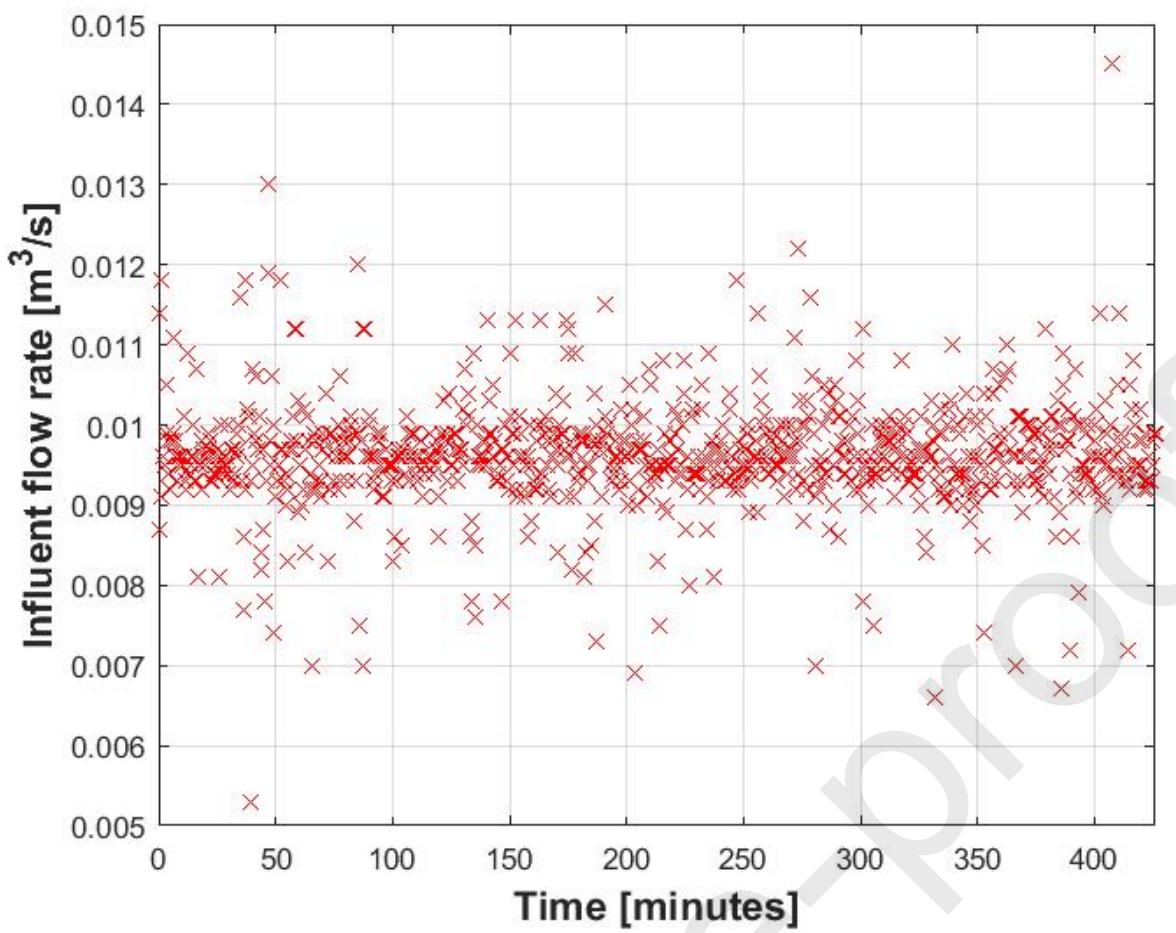

(a)

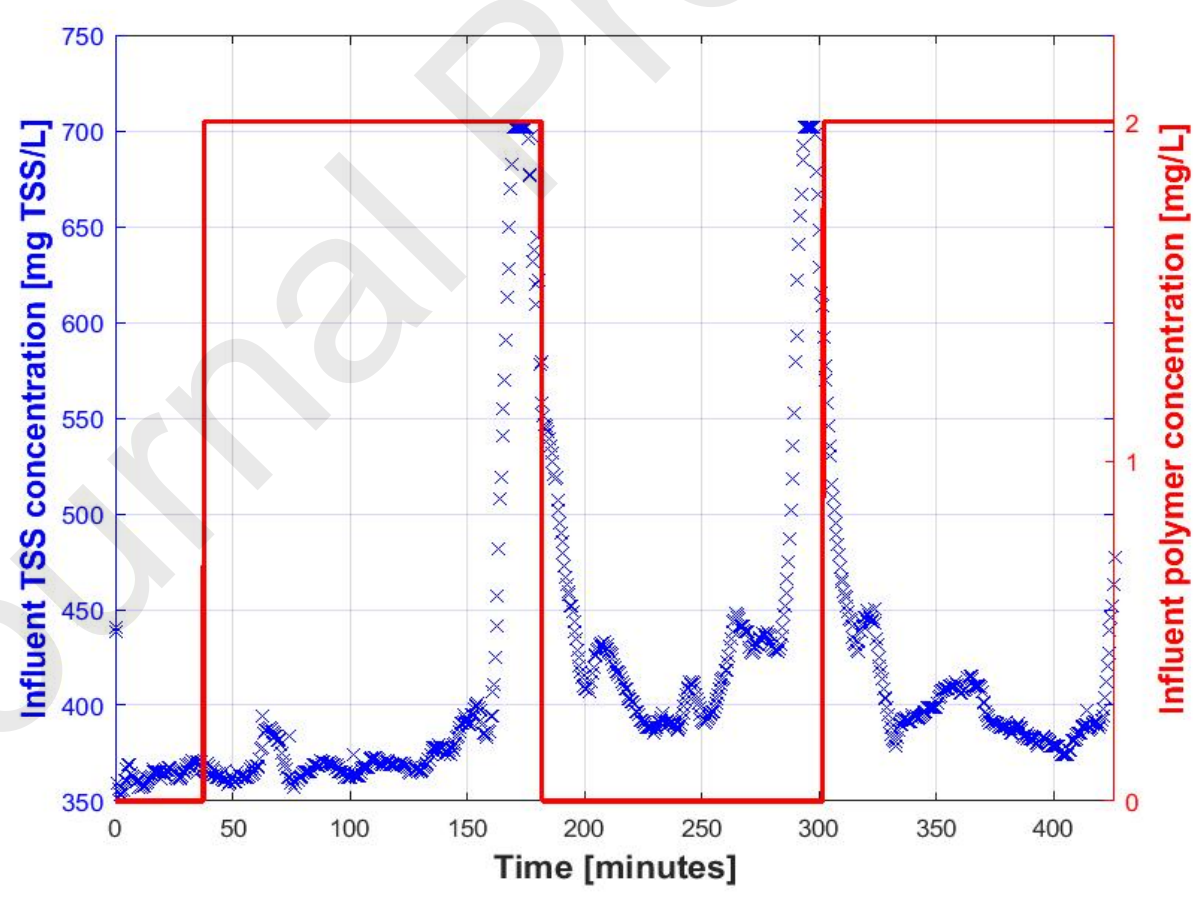

(b)

Figure 7: (a) Influent flow rate, and (b) influent TSS and influent polymer concentrations (in blue and in red, respectively) used as model inputs during model calibration. Time $=0$ 
corresponds to $9 \mathrm{am}$; the two TSS peaks are typical diurnal TSS peaks observed in the inlet to the WWTP.

Model parameters are adjusted using a Monte Carlo (MC) framework following the procedure published by Sin et al. (2008). Specifically, parameters are systematically perturbed using the Latin Hypercube Sampling (LHS) method, initially considering broad ranges (upper and lower bounds) for each parameter in the model calibration set. For each generated MC sample of the model parameter set a model simulation is run. The sum of the squared scaled differences between predictions and data is calculated for both belt speed and filtered TSS concentration to quantify the two errors ( $e_{\text {Beltspeed }}$ and $e_{T S S f i t t e r e d}$, respectively), as expressed in Eqn. (29), where $n$ is the number of observations and $S F_{\text {BeltSpeed }}$ and $S F_{T S S}$ are the scaling factors for the belt speed and filtered TSS errors, respectively. The values for those two scaling factors were chosen to be 100 and 1000 for the belt speed error and the filtered TSS error respectively, with the aim of having the errors on both variables to be close to the order of magnitude of one, thus enabling equal weighting of both data sets during the parameter estimation, and resulting in easier visualization of the discrepancies with the data.

$$
\left\{\begin{array}{c}
e_{\text {BeltSpeed }}=\sum_{i=1}^{n}\left[\frac{1}{S F_{\text {BeltSpeed }}} \cdot\left(S_{\text {belt }, i}-S_{\text {belt }, \text { data }, i}\right)\right]^{2} \\
e_{\text {TSSfiltered }}=\sum_{i=1}^{n}\left[\frac{1}{S F_{T S S}} \cdot\left([T S S]_{\text {filtered }, i}-[T S S]_{\text {filtered,data }, i}\right)\right]^{2}
\end{array}\right.
$$

The MC samples leading to low values of $e_{\text {BeltSpeed }}$ and $e_{\text {TSSfittered }}$ are identified as guess optimal parameter sets.

In the next iteration, a new set of samples is generated, according to the LHS technique, by redefining an upper and lower bound for each parameter around the guess optimal parameter sets 
obtained in the preceding step. Model simulations are run, the two errors of Eqn. (29) are calculated again, and other guess optimal parameter sets are again identified. The procedure is repeated until the two errors cannot be minimized any further. The parameter sample leading to the lowest error in belt speed and filtered TSS concentration is identified as the optimal model calibration set. The final optimized parameter values identified can be found in Appendix A.

During model calibration, the upstream heights predicted by the model and from plant operation were able to match each other by adjusting the overflow discharge coefficient $\left(C_{d}^{o f}\right)$ to a value of 0.25 .

Results for the upstream height, in relation to its set point of 0.44 meters, predicted by the calibrated model and during system operation are displayed in Figure 8. As can be seen, the set point is tracked both during model simulation and during plant operation. The ability to control the upstream water level to its set point is better during model simulation, as no measurement error or delay is included. As depicted, from minute 165 to 185 , overflow occurred due to the increased influent TSS concentration and the injection of polymer. 


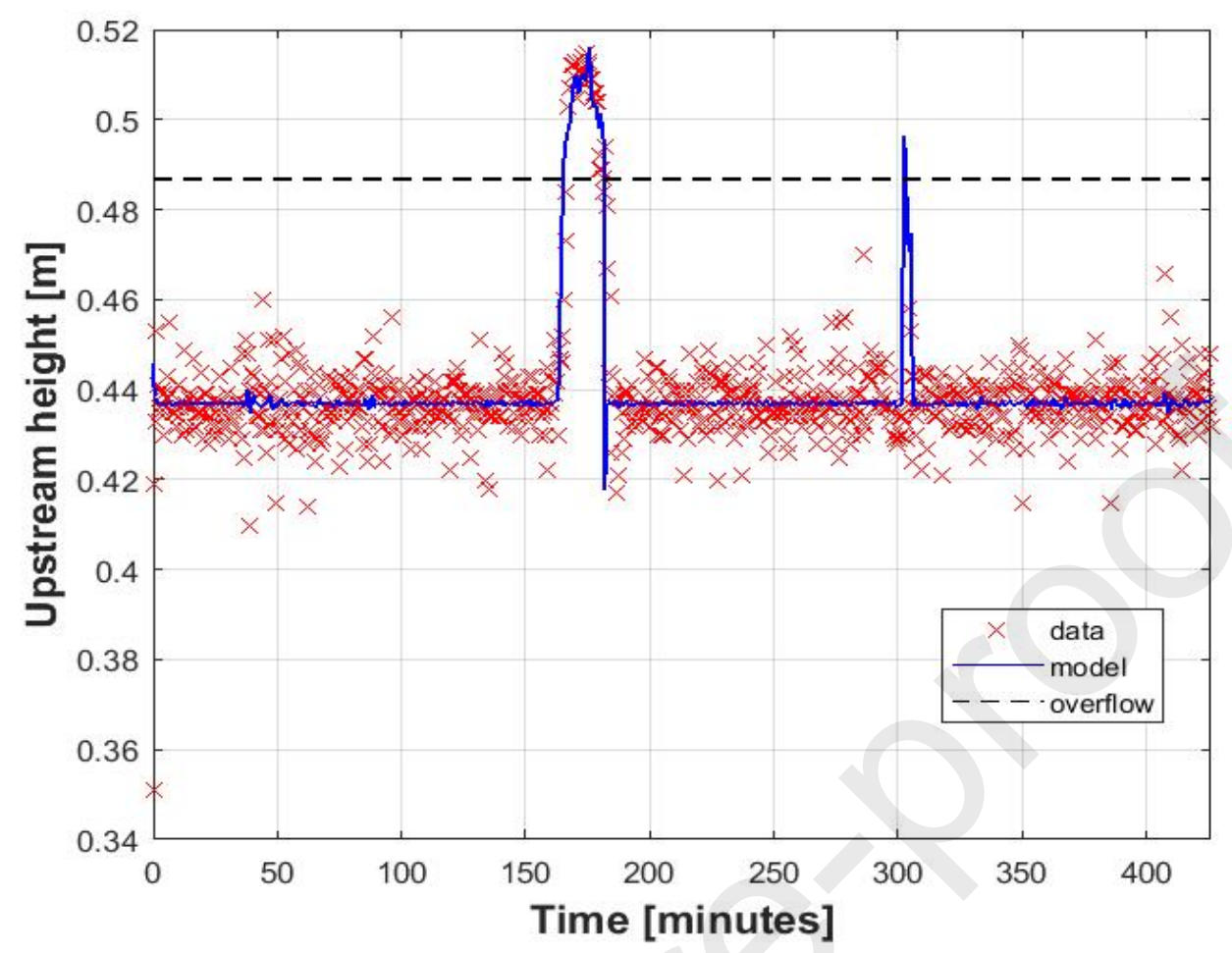

Figure 8: Simulated level control by the RBF model with polymer effect (in blue), and pilot scale level data (in red) collected for model calibration.

Calibration results in terms of belt speed control response and filtered TSS concentration are presented in Figure 9. The discrepancy between the predicted belt speed response and the collected data is quantified with the error $e_{\text {Beltspeed }}$ equal to 0.52 while $e_{\text {TSSfittered }}$ is 0.15 . With regard to the belt speed response (see Figure 9a), the results show that the parameters have been optimized in order to replicate accurately the data collected. However, a higher overall disturbance of the belt speed predicted by the model compared to the data could be noted. This can be attributed to the use of influent flow rate data with measurement noise (see Figure 7a) and due to the different behaviour of the controller during model simulation which reacts continuously to deviations from the set points. Apart from these differences, it can be clearly seen that the trend of belt response is 
completely in line with the data, both in the case where the polymer is added and in the case where it is not. With regard to the filtered TSS concentration (see Figure 9b), it can be noted that two peaks (one from minute 160 to 180 , and the other one from minute 280 to 300 ) were not able to be reliably replicated by the model. This has been attributed to a limitation of the probe measuring the influent TSS concentrations while collecting the data, which could not measure values beyond $700 \mathrm{mg}$ TSS.L $\mathrm{L}^{-1}$, a TSS concentration which was likely exceeded during these events. Such data resulted in an underestimation of the filtered TSS by the model since those measurements were used as inputs during the simulations. Apart from these two peaks, all the other filtered TSS measurements could be accurately replicated by the model.

Summarizing, the parameters have been optimized in such a way that both the hydrodynamic regime and the TSS removal recorded during a day of RBF system operation are represented by the model with satisfactory agreement. However, this is not enough to prove that the model can realistically predict these important outputs when other influent data sets are used instead. With the aim of assessing the capability of the calibrated model in replicating other sets of data, a validation is performed, which is presented in the next section. 


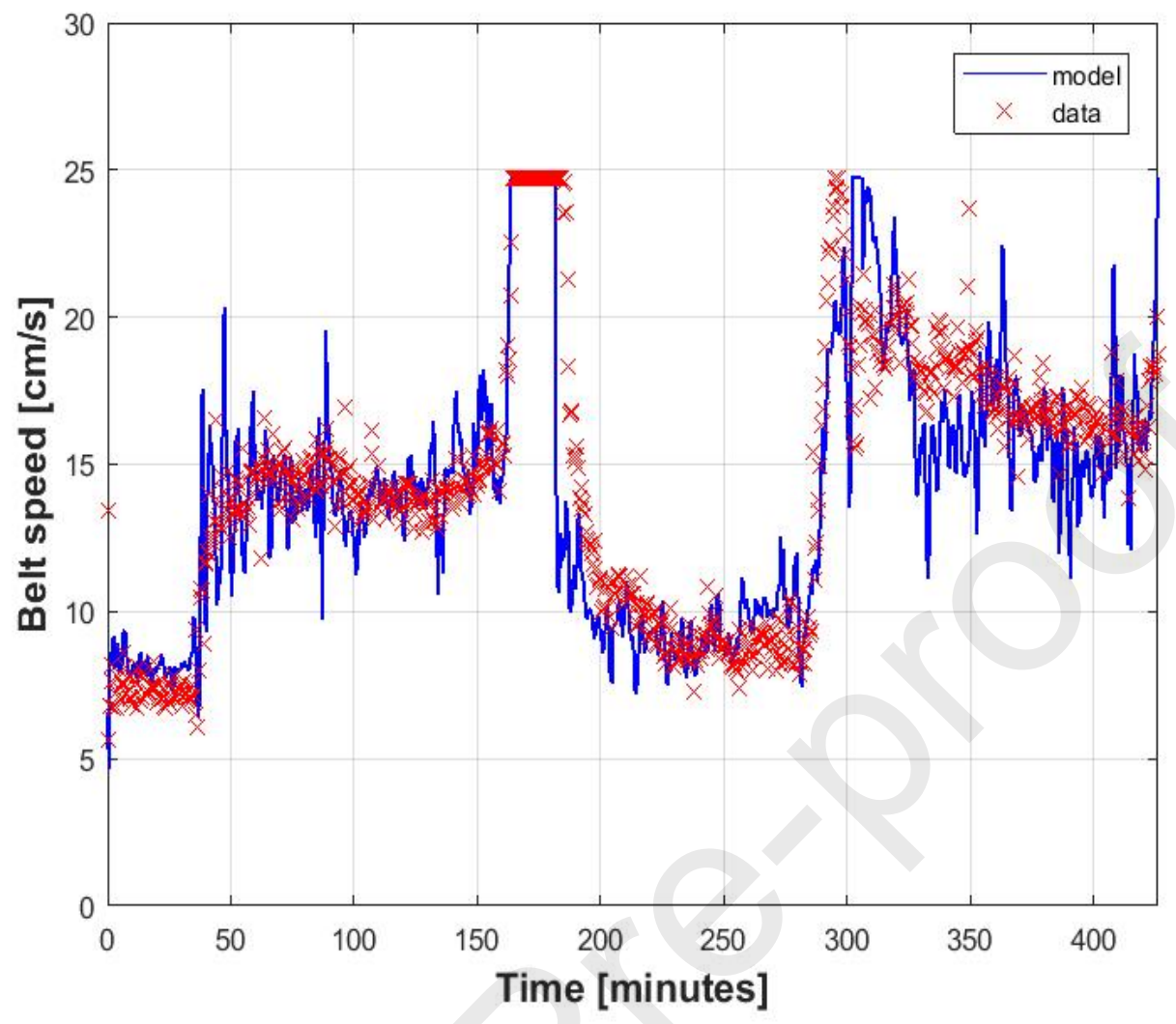

(a) 


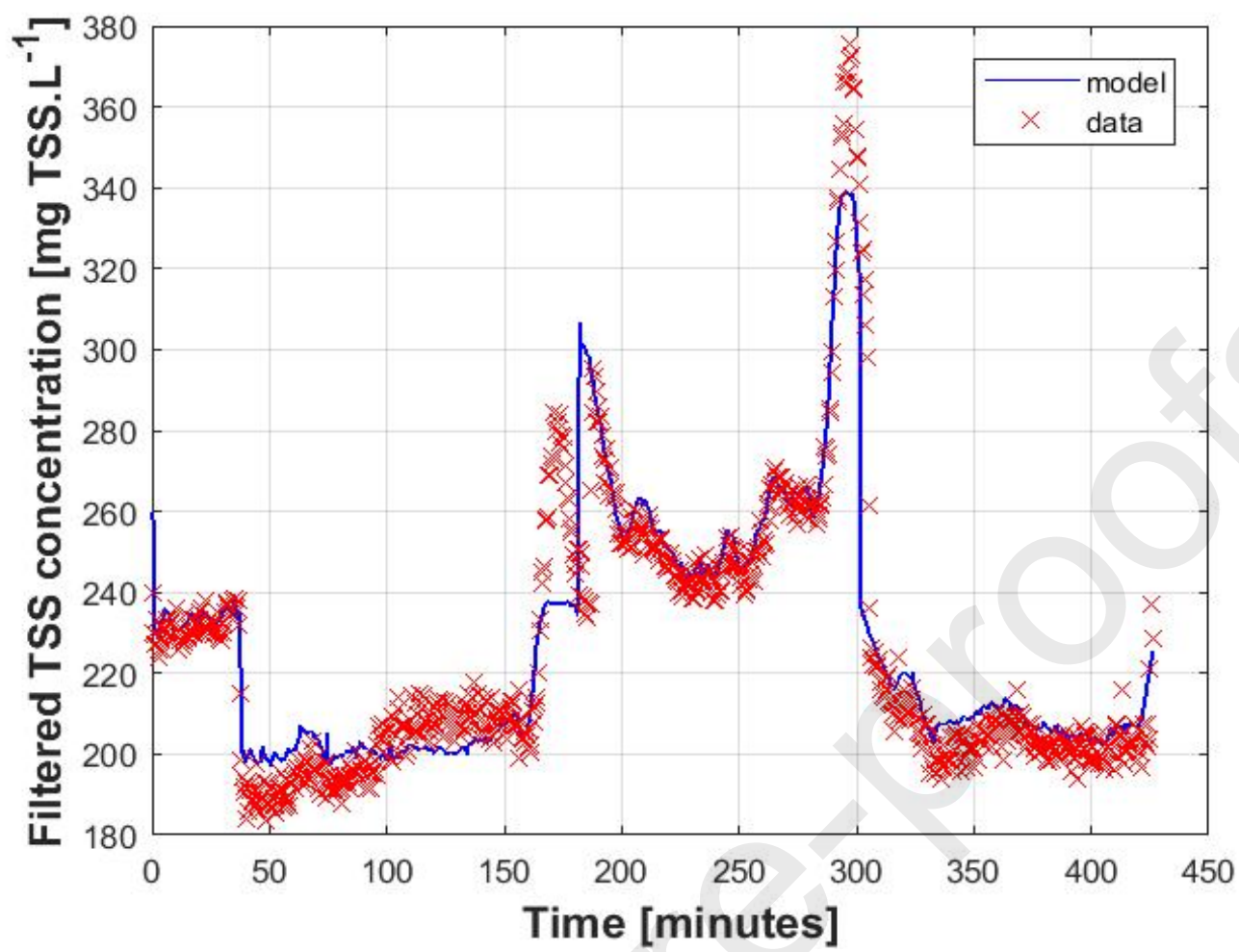

(b)

Figure 9: (a) Control system dynamic response of belt speed, and (b) filtered TSS concentration from model (in blue) and data collection (in red) achieved during model calibration.

\subsection{Model validation}

For the validation case, the model with the optimized parameters is run using an independent input data set collected during another day of Salsnes filter SF2000 operation and is presented in Figure 10. 


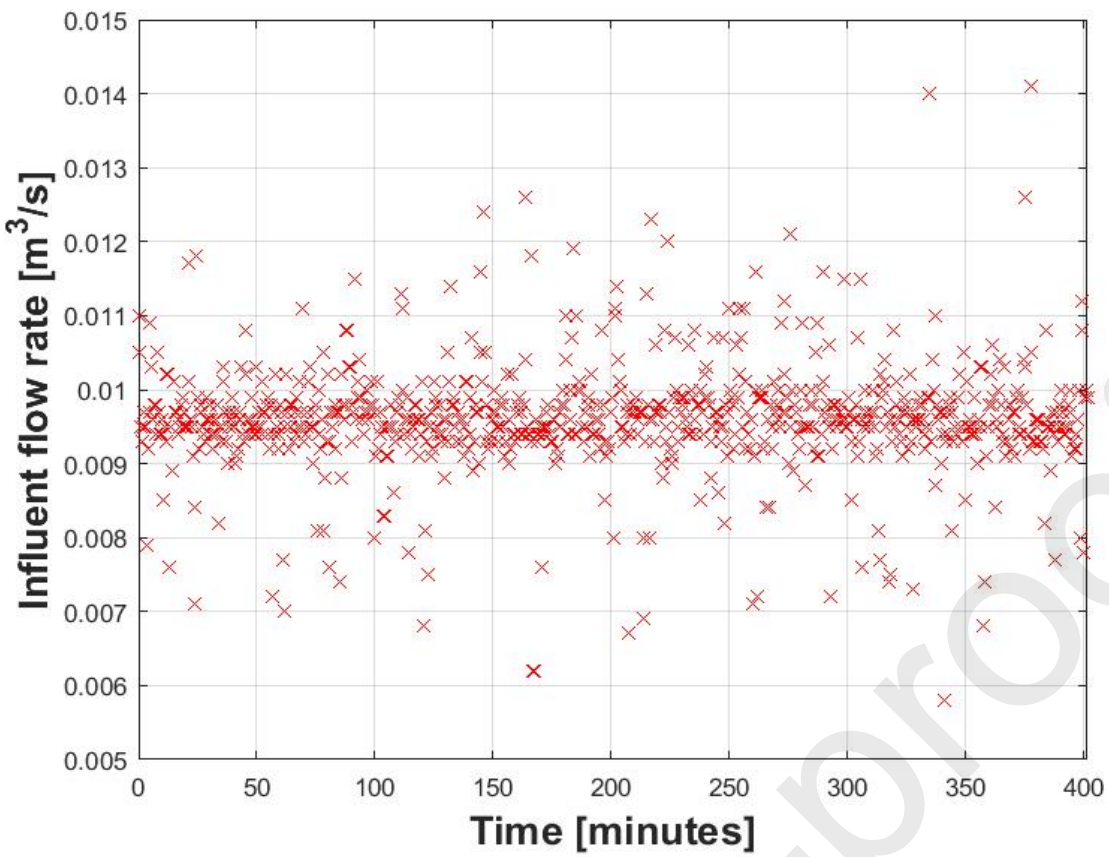

(a)

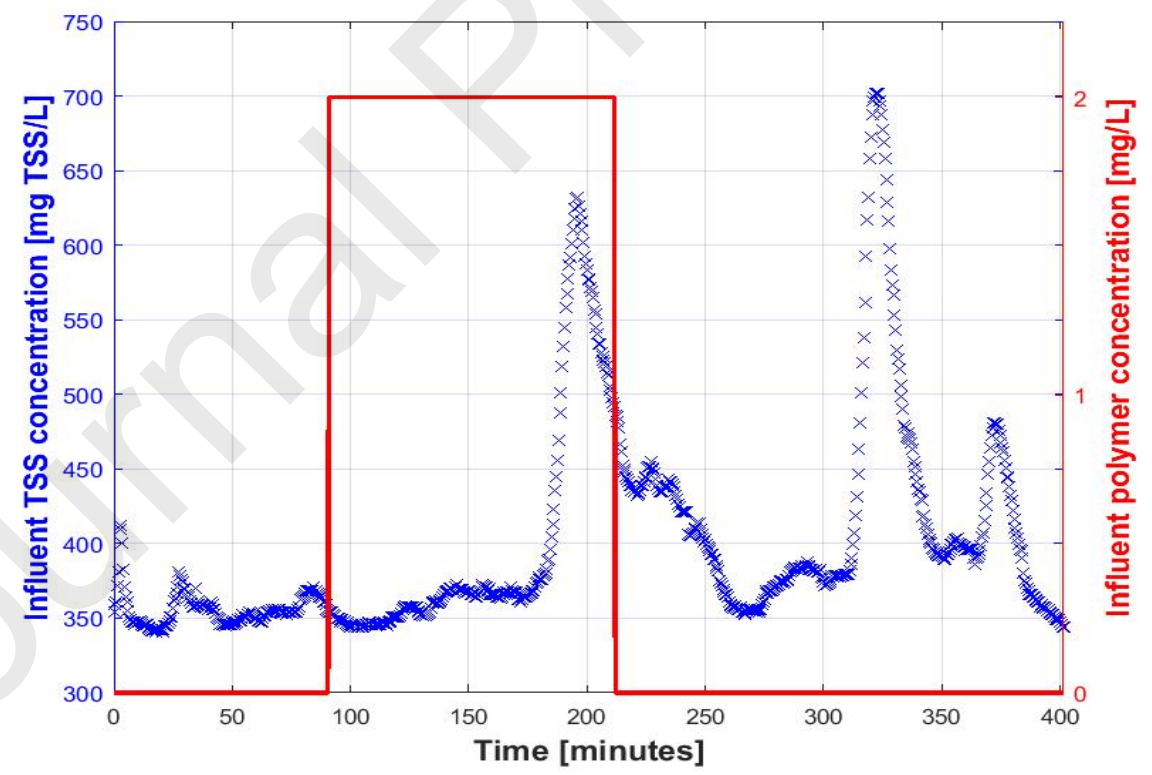

(b)

Figure 10: (a) Influent flow rate, and (b) influent TSS and influent polymer concentrations in the data set used as model inputs during RBF model validation. 
Figure 11 shows that the upstream height set point is tracked both in the case of real plant operation and during the simulation of the calibrated model. Similarly to the calibration case, the set point is better tracked during model simulation. By examining Figure 11, it can also be noted that the height measurements during the overflow period can be tracked by the model using the same discharge coefficient value as the one obtained during model calibration.

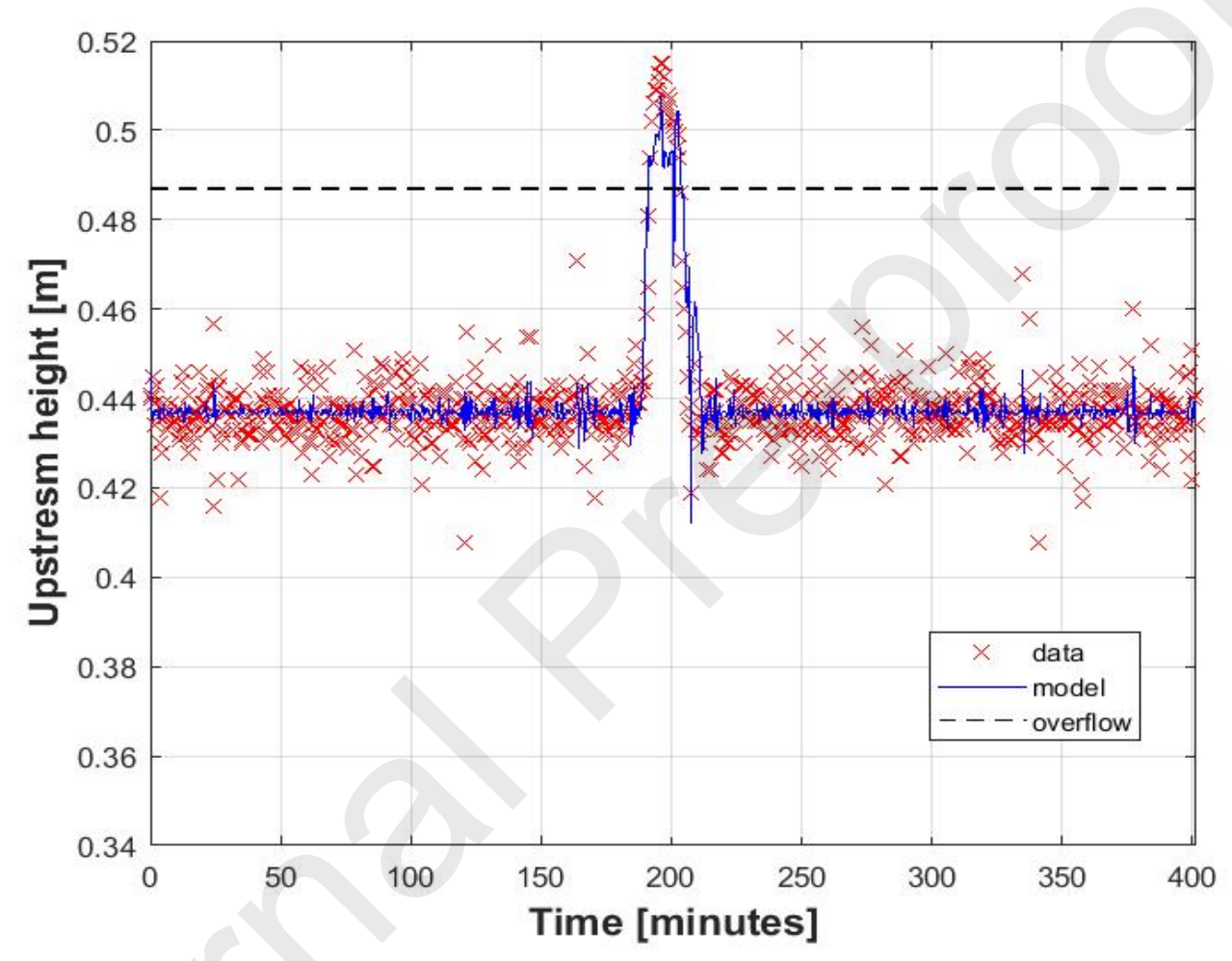

Figure 11: Simulated level control by the RBF model with polymer effect (in blue), and pilot scale level data (in red) collected for model calibration.

As can be seen from Figure 12, showing the belt speed response and the filtered TSS concentration, the model shows its ability to describe the data collected without any need to adjust the optimized parameters both in terms of hydrodynamics and in terms of TSS removal performance. In this case, $e_{\text {BeltSpeed }}$ was 0.49 while $e_{T S S f i t e r e d}$ was 0.18 . Compared to the errors of the calibration case, it can 
be said that the belt speed response is replicated slightly better while the filtered TSS concentration is described slightly worse. These validation results indicate that the model described in Section 3 with the optimized parameters can be used with different influent composition data.

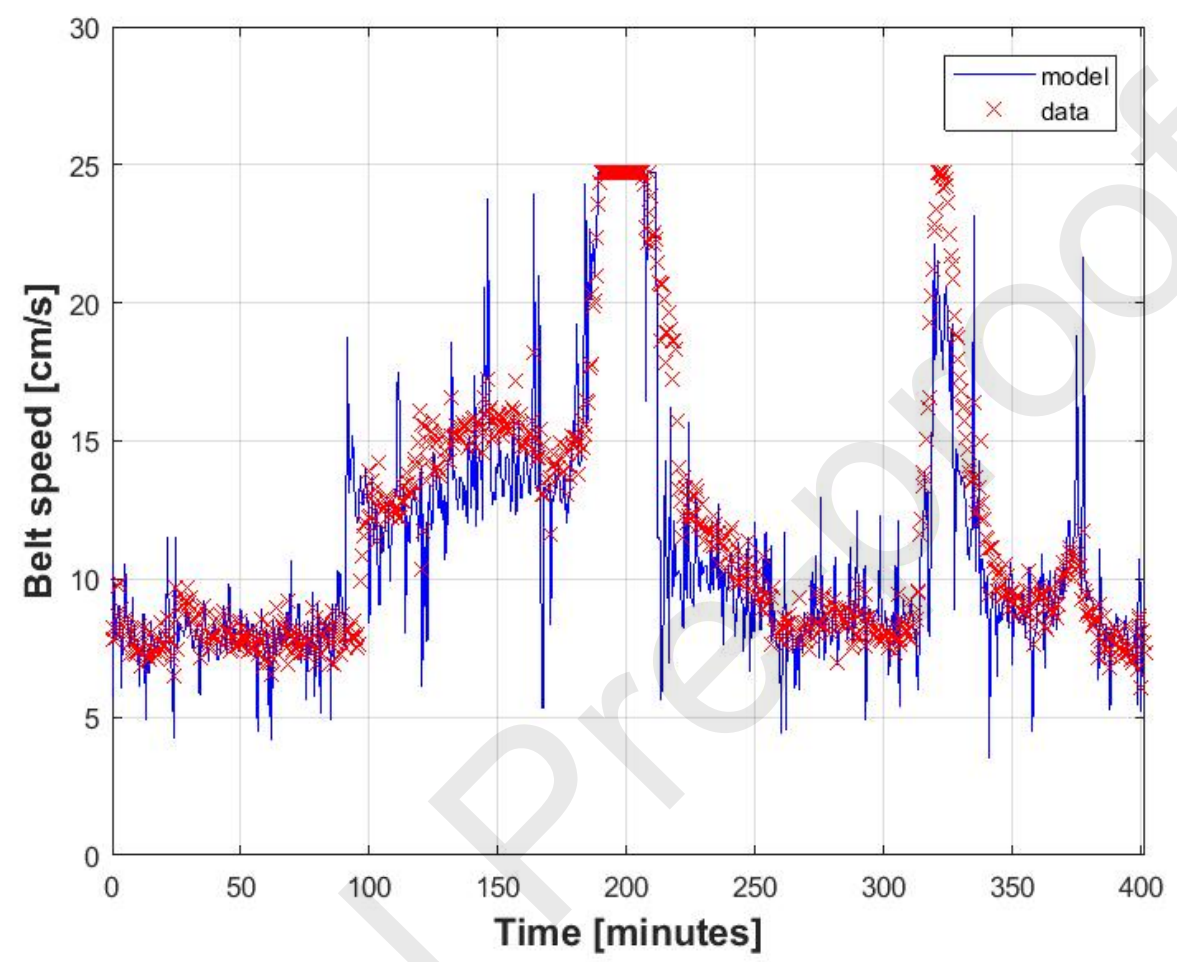

(a) 


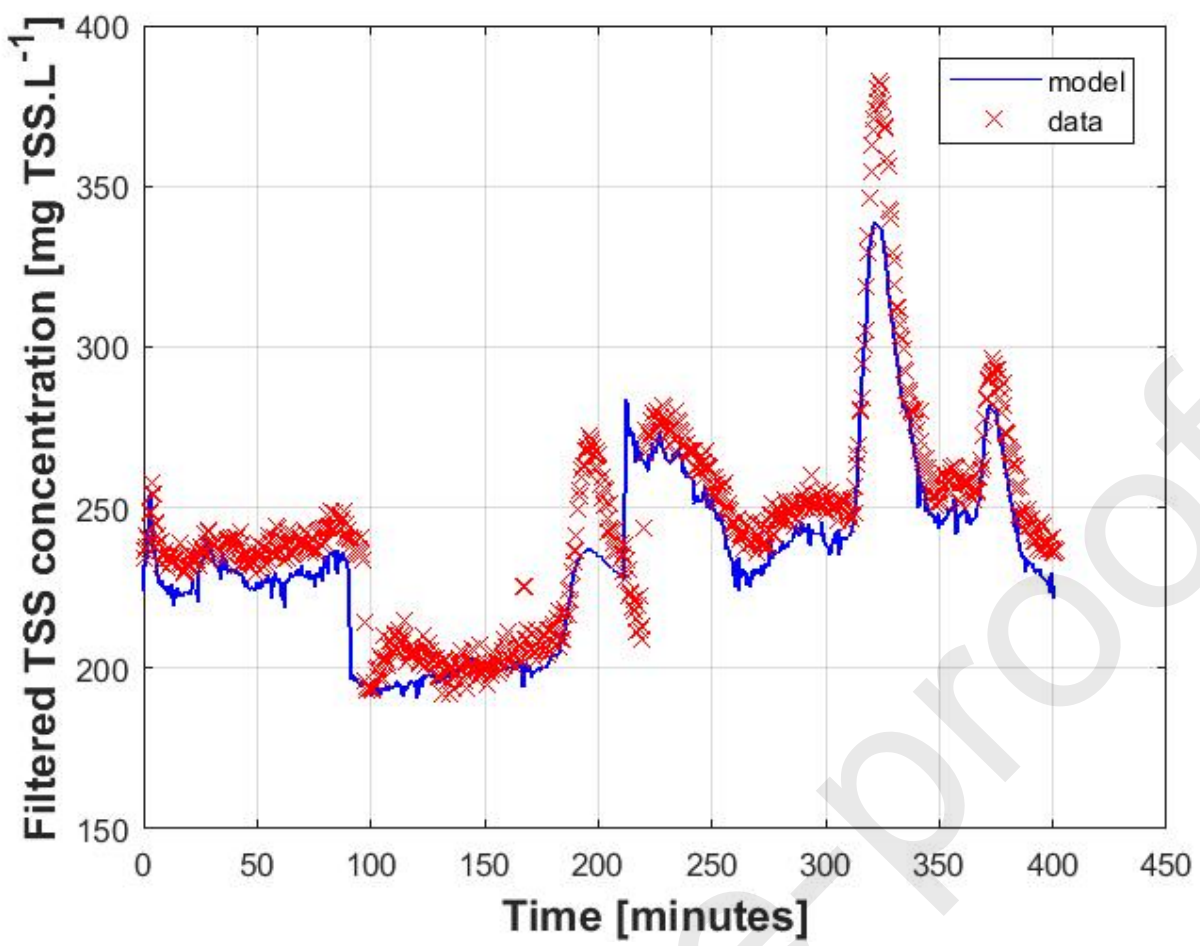

(b)

Figure 12: (a) Control system dynamic response of belt speed, and (b) filtered TSS

concentration from model (in blue) and data collection (in red) achieved during model validation.

\section{Polymer-addition control strategy}

A patent-pending control strategy (US20180318736A1), conceived for optimizing the RBF system with polymer pre-treatment, is implemented in the model and tested in conjunction with the default upstream water level controller. Specifically, the new control logic relies on adding polymer as a function of the particle loading as indirectly indicated by the instantaneous belt speed and the instantaneous flow rate. As such, the newly-implemented control strategy is based on exploiting the difference between the maximal value of belt speed of the machine and the actual value of belt speed imposed by the water level controller. The ideal amount of polymer to have in the influent to the system is identified in order to achieve the highest belt speed that the machine can have 
without having overflows. A schematic representation of this control strategy is depicted in Figure 13 while the parameter values are presented in Table 2. Dynamic responses of the RBF system implemented with such a control strategy and its ability in tracking the belt speed set point can be found in Appendix B.

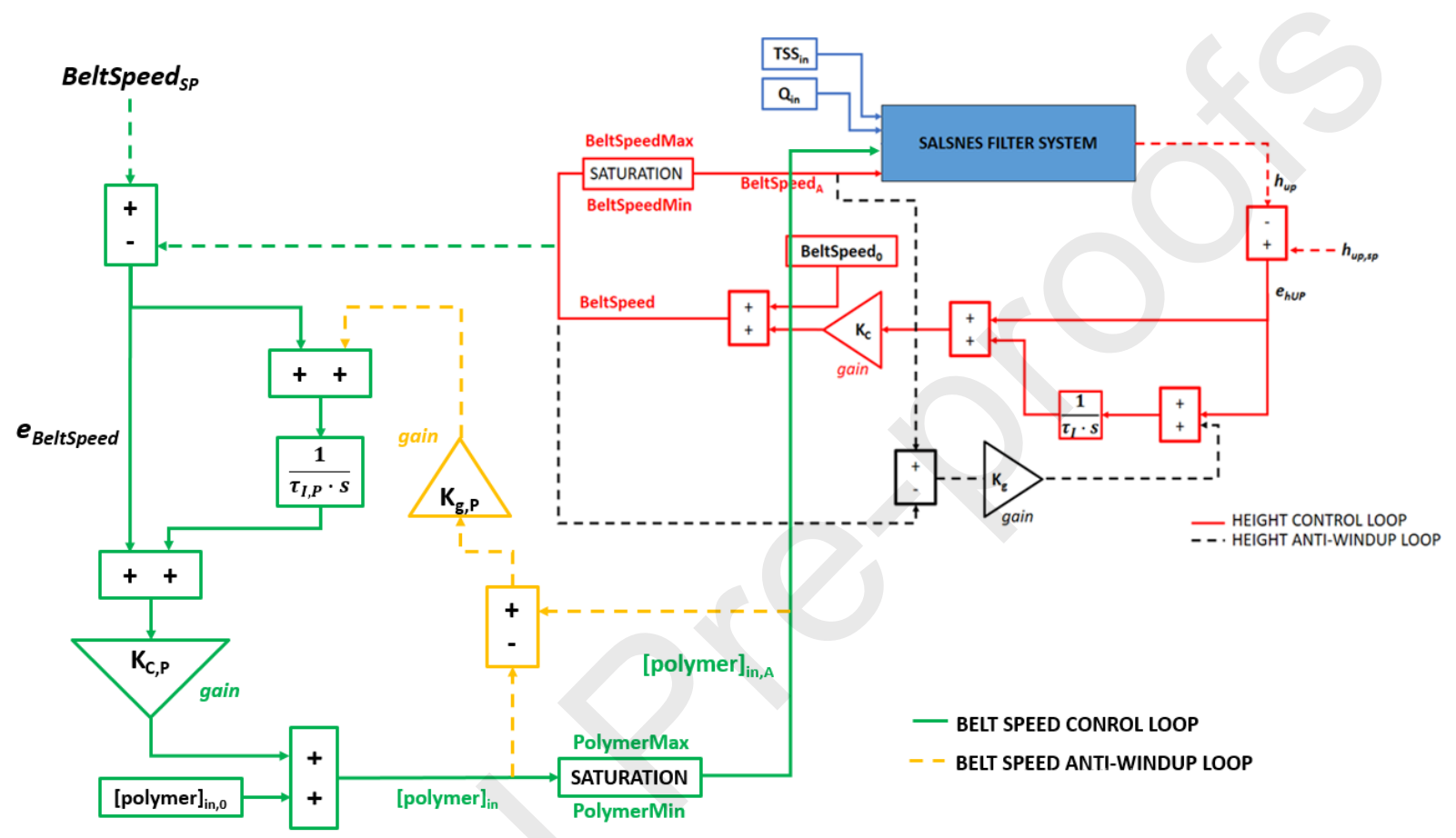

Figure 13: RBF system model with controllers for upstream water level (in red and black) and belt speed (in green and yellow). 
Table 2: Parameter values used for the loop controlling the belt speed by regulating polymer addition.

\begin{tabular}{|c|c|c|c|}
\hline Parameter & Symbol & Value & Unit of measurement \\
\hline Proportional Gain & $\mathrm{K}_{\mathrm{C}, \mathrm{P}}$ & 6.5 & {$[\mathrm{mg}$ polymer/L/(cm/s) $]$} \\
\hline Integral time constant & $\tau_{\mathrm{I}, \mathrm{P}}$ & 0.072 & {$[\mathrm{~min}]$} \\
\hline Anti-windup gain & $\mathrm{K}_{\mathrm{g}, \mathrm{P}}$ & 0.31 & {$[(\mathrm{~cm} / \mathrm{s}) /(\mathrm{mg}$ polymer/L $)]$} \\
\hline Nominal influent polymer concentration & {$[\text { polymer }]_{\mathrm{in}, 0}$} & 0 & {$[\mathrm{mg}$ polymer $/ \mathrm{L}]$} \\
\hline Minimum influent polymer concentration & PolymerMin & 0 & {$[\mathrm{mg}$ polymer/L] } \\
\hline Maximum influent polymer concentration & PolymerMax & 7 & {$[\mathrm{mg}$ polymer/L] } \\
\hline
\end{tabular}

\section{Plant-wide impact assessment of RBF systems}

The end goal of the impact assessment performed in this work is to evaluate the possible added value and drawbacks of RBF technologies to full-scale WWTPs in terms of aeration energy demand in the activated sludge (AS) compartment, methane gas production, effluent quality, sludge disposal, and nitrous oxide $\left(\mathrm{N}_{2} \mathrm{O}\right)$ emissions. The energy demand due to aeration is calculated assuming that Degrémont DP230 porous disks immerged under four meters of water are used as aerators, such that one kilowatt-hour of energy is consumed per 1.8 kilos of oxygen transferred, as according to the BSM2 protocol. Energy consumption linked to utilities other than the aerators are not considered in this work. This is because their characterization depends too much on local factors among which the equipment used, the location of the wastewater treatment plant and the source of energy. An overall energetic balance will therefore be too case specific and subject to high degree of uncertainty. The purpose of the plant-wide assessment proposed in this work is to highlight qualitatively the main advantages and disadvantages due to the adoption of 
RBF technology in an unbiased way, while the overall actual energetic expenses are left open to quantification and will vary from case to case.

Specifically, it is of interest to study how RBF systems can impact WWTP performance when included in plants where no primary treatment currently exists, when installed in place of an existing primary clarifier, or when performance enhancing strategies, such as polymer addition, are implemented. For this evaluation, model results describing each of the following scenarios are benchmarked against one another:

a) Scenario $1(S 1)$ : a full-scale WWTP without any primary treatment,

b) Scenario $2(S 2)$ : a full-scale WWTP with a primary clarifier,

c) Scenario $3(S 3)$ : a full-scale WWTP with a RBF system without added polymer,

d) Scenario $4(S 4)$ : a full-scale WWTP with the RBF system of $S 3$ with a fixed influent concentration of polymer,

e) Scenario $5(S 5)$ : a full-scale WWTP with the on-line control strategy regulating polymer addition described in Section 5.

The models corresponding to each of these scenarios are built up starting from the Benchmark Simulation Model No2 (BSM2) by Jeppsson et al. (2007), extended in order to incorporate $\mathrm{N}_{2} \mathrm{O}$ production processes in the mainstream activated sludge unit described by Domingo-Felez ( 2017), as reported by Boiocchi et al. (2017). The choice of the model by Domingo-Felez (2017) is in virtue of a more comprehensive description of $\mathrm{N}_{2} \mathrm{O}$ production in WWTPs compared to other models such as the Activate Sludge Model for Greenhouse Gases $n^{\circ} 1$ by Guo and Vanrolleghem (2014) or the model by Ni et al. (2013). The model by Otterpohl et al. (1994) is used to describe the solid settling processes occurring in the primary clarifier for $S 2$, as in the original BSM2 (Gernaey et al., 2014). The dynamic RBF model presented in Sections 3 is used to describe the 
primary treatment along with the typical controller setting the upstream water level at 0.44 meters for scenarios $S 3, S 4$ and $S 5$. For $S 5$, the set point value for the belt speed used is $23.2 \mathrm{~cm} / \mathrm{s}$, chosen to be lower than the maximal value in order to avoid overflows in case of fast influent dynamics. A novel dynamic specification for the removal efficiencies of the different particulate components is introduced here according to the measurement campaign by Gupta (2018). During the campaign at the Greenway Wastewater Treatment Center, measurements of different COD fractions and TSS were taken in the influent to the primary treatment and in the effluent from both a primary clarifier and the parallel Salsnes Filter SF2000 from where the data were collected for model calibration and validation. Appendix $\mathrm{C}$ describes how these data have been processed to identify the removal efficiencies of the different model variables on the basis of the TSS removal predicted by both the primary clarifier and the RBF system.

\subsection{Impact assessment results}

The five plant-wide models describing the previously-mentioned scenarios are run by controlling the oxygen in the three aerobic tanks at a concentration of $1 \mathrm{mg} \mathrm{L}^{-1}$ and the TSS concentration in the last aerobic tank is kept at $3000 \mathrm{mg} \mathrm{TSS} \mathrm{L}^{-1}$ in order to achieve comparability. Steady-state

results are presented in Table 3. Given the lower TSS removal by the RBF system without polymer addition (S3) compared to the case when a primary clarifier was used instead, the polymer concentration in the influent to the RBF of $S 4$ was optimized with the aim of achieving the same steady-state TSS removal efficiency of the PC, such that the two types of technologies, PC and RBF system, could be compared despite different TSS removal capabilities. It resulted in an ideal value of $3.05 \mathrm{mg}$ polymer. $\mathrm{L}^{-1}$. When the on-line control strategy for polymer addition was 
introduced for $S 5$, the steady-state influent polymer concentration achieved was $5.6 \mathrm{mg}$ polymer.L1.

Analysing the results presented, it can be noted that, as more TSS are removed, there is a reduced energy demand for aeration in the AS unit. This is expected since, when more TSS are removed, a higher biodegradable COD fraction of the influent is diverted to the side-stream treatment. It can therefore be said that PCs lead to better aeration savings than RBF technologies when the latter have no polymer addition. However, for the same TSS removal efficiency (i.e. comparing $S 2$ against S4), the adoption of RBF systems shows slightly better aeration energy savings than the PC, due to the higher removal of slowly-biodegradable COD in the RBF system compared to the PC (see Tables C.2 and C.3 in Supplementary Information). The scenario with the RBF system supplied with the optimized polymer addition had the highest TSS removal efficiency, which in turn led to the lowest aeration energy demand among all the scenarios. As more organic carbon is diverted to the anaerobic digestion unit, higher methane productions are recorded at higher TSS removal efficiencies by the primary treatment and, TSS removal being equal, higher methane productions are predicted in plant configurations with RBF systems, which is confirmed by Paulsrud et al. (2014).

With regard to the sludge production for disposal, differences among the different scenarios are negligible. Sludge production is largely affected by the amount of particulate COD in the influent to the anaerobic digester and by the capability of this digester in converting this COD fraction into methane. The non-biodegraded fraction of COD will mostly become sludge for disposal. Table 3 reports the total particulate $\mathrm{COD}$ in the influent to the $\mathrm{AD}$ unit and its biodegradability. From the results obtained, it can be observed that, although the anaerobic digester in the scenarios with a primary treatment receives considerably more particulate organic carbon than the anaerobic 
digester of the scenario without any primary treatment, this does not impact significantly the production of sludge for disposal. This is because the added amount of COD which is fed to the anaerobic digester is converted into methane. This can be clearly observed by looking at the higher methane productions achieved when a primary treatment unit is included.

With regard to the effluent TN concentration, which consists of mainly nitrates in the effluent due to the pre-denitrification configuration of the AS compartment in the BSM2, it can be observed that diverting more biodegradable organic carbon to the anaerobic digestion increases the amount of $\mathrm{TN}$ in the effluent as less organic carbon is available as electron donor for nitrate reduction in the mainstream treatment compartment. This explains the highest effluent TN values achieved when the RBF system with polymer addition control is used. It can be further observed that the set point for the belt speed used in this control strategy should not be fixed to a high value all the time but regulated in order to meet the wastewater treatment plant water quality requirements. Total effluent ammonia nitrogen, which is a very small contribution compared to the effluent $\mathrm{TN}$, is relatively higher when no primary treatment is included, as the higher amount of carbon fed to the AS compartment consumes part of the oxygen that would otherwise be consumed by ammoniaoxidizing bacteria (AOB) for ammonia oxidation.

The impact of primary treatment technologies on $\mathrm{N}_{2} \mathrm{O}$ emissions is here studied in relation to the reduction of the amount of organic biodegradable carbon fed to the activated sludge unit due to the implementation of the particular technology implemented. From the resulting $\mathrm{N}_{2} \mathrm{O}$ productions by both $\mathrm{AOB}$ and $\mathrm{HB}$ and the accumulation in the aerobic compartment of hydroxylamine $\left(\mathrm{NH}_{2} \mathrm{OH}\right)$, it emerges that the scenario without a primary treatment technology has the highest $\mathrm{N}_{2} \mathrm{O}$ production by $\mathrm{AOB}$ as a consequence of $\mathrm{NH}_{2} \mathrm{OH}$ accumulation. $\mathrm{NH}_{2} \mathrm{OH}$ is an intermediate chemical of aerobic ammonia oxidation which can be used by AOB as an electron donor during 
nitrite and nitric oxide enzymatic reduction, forming $\mathrm{N}_{2} \mathrm{O}$ as an end product. If the anoxic compartment receives an excessive amount of carbon, the fraction of carbon not utilized by the heterotrophic biomass to reduce nitrogen oxides is fed to the aerobic compartment, limiting autotrophic bacteria. Thus, when no primary treatment is used, the larger amount of organic carbon fed to the aerobic compartment prevents the complete aerobic oxidation of ammonia to nitrite, thus leading to accumulation of intermediates such as $\mathrm{NH}_{2} \mathrm{OH}$. This in turn triggers $\mathrm{N}_{2} \mathrm{O}$ production by AOB with nitric oxide as electron acceptor. Although the consumption of $\mathrm{N}_{2} \mathrm{O}$ by $\mathrm{HB}$ in the aerobic zone is higher when no primary treatment unit is used, this is only a minor contribution to the overall $\mathrm{N}_{2} \mathrm{O}$ emissions. It follows that the highest total $\mathrm{N}_{2} \mathrm{O}$ emissions occur when no primary treatment is used while the differences in $\mathrm{N}_{2} \mathrm{O}$ emissions are negligible among those scenarios when a primary treatment unit is used. However, it should be pointed out that these considerations are influenced by the $\mathrm{N}_{2} \mathrm{O}$ producing processes included in the AS model adopted in this study. Hence, more work and full-scale investigations are needed in order to confirm these model-based observations on the impact of primary treatment technologies on $\mathrm{N}_{2} \mathrm{O}$ emissions.

Table 3: Model-based benchmarking for Scenarios 1, 2, 3, and 4 in terms of aeration demand, methane production, sludge production, effluent $\mathrm{TN}$ concentration, effluent total ammonia concentration, hydroxylamine accumulation and total $\mathrm{N}_{2} \mathrm{O}$ emissions and $\mathrm{N}_{2} \mathrm{O}$ productions by $\mathrm{AOB}$ and $\mathrm{HB}$.

\begin{tabular}{|c|c|c|c|c|c|c|}
\hline & $\begin{array}{c}\text { Unit of } \\
\text { measurement }\end{array}$ & $\begin{array}{c}\text { No } \\
\text { Primary } \\
\text { Treatment } \\
(\boldsymbol{S} 1)\end{array}$ & $\begin{array}{c}\text { Primary } \\
\text { clarifier } \\
(\boldsymbol{S} 2)\end{array}$ & $\begin{array}{c}\text { Rotating } \\
\text { belt } \\
\text { filters } \\
(S 3)\end{array}$ & $\begin{array}{c}\text { Polymer } \\
\text { added } \\
\text { Rotating } \\
\text { belt } \\
\text { filters } \\
(S 4)\end{array}$ & $\begin{array}{c}\text { Polymer } \\
\text {-dosing } \\
\text { Control } \\
\text { Strategy } \\
(S 5)\end{array}$ \\
\hline $\begin{array}{c}\text { TSS removal } \\
\text { by the }\end{array}$ & {$[\%]$} & 0 & 51.4 & 37.3 & 51.4 & 61.5 \\
\hline
\end{tabular}




\begin{tabular}{|c|c|c|c|c|c|c|}
\hline $\begin{array}{c}\text { primary } \\
\text { treatment }\end{array}$ & & & & & & \\
\hline $\begin{array}{c}\mathrm{COD}_{\text {bio }} / \mathrm{COD} \\
\text { influent to } \mathrm{AD}\end{array}$ & {$[-]$} & 0.57 & 0.69 & 0.66 & 0.69 & 0.71 \\
\hline $\begin{array}{c}\text { Influent } \\
\text { pCOD load to } \\
\text { AD }\end{array}$ & {$\left[\mathrm{kg} \mathrm{COD} \cdot \mathrm{d}^{-1}\right]$} & 6549.6 & 8097.1 & 7631 & 8134.3 & 8524.8 \\
\hline $\begin{array}{c}\text { Aeration } \\
\text { energy } \\
\text { demand }\end{array}$ & {$\left[\mathrm{kWh} \cdot \mathrm{d}^{-1}\right]$} & 5028.0 & 4206.6 & 4407.6 & 4186.05 & 4021.2 \\
\hline $\begin{array}{c}\text { Methane } \\
\text { production }\end{array}$ & {$\left[\mathrm{kg} \mathrm{COD} \cdot \mathrm{d}^{-1}\right]$} & 765.3 & 1201.2 & 1099.5 & 1219.3 & 1309.5 \\
\hline $\begin{array}{c}\text { Sludge } \\
\text { production }\end{array}$ & {$\left[\mathrm{kg} \mathrm{COD} \cdot \mathrm{d}^{-1}\right]$} & 2346.3 & 2360.4 & 2323.9 & 2341.1 & 2355.7 \\
\hline $\begin{array}{c}\text { Effluent TN } \\
\text { concentration }\end{array}$ & {$\left[\mathrm{g} \mathrm{N} \cdot \mathrm{m}^{-3}\right]$} & 11.15 & 16.84 & 14.9 & 17.17 & 19 \\
\hline $\begin{array}{c}\text { Effluent total } \\
\text { ammonia } \\
\text { nitrogen } \\
\text { concentration }\end{array}$ & {$\left[\mathrm{g} \mathrm{N} \cdot \mathrm{m}^{-3}\right]$} & 0.3 & 0.016 & 0.025 & 0.016 & 0.012 \\
\hline $\begin{array}{c}\mathrm{NH}_{2} \mathrm{OH} \\
\text { accumulation } \\
\text { in aerobic } \\
\text { compartment }\end{array}$ & {$\left[\mathrm{g} \mathrm{N} . \mathrm{m}^{-3}\right]$} & 1.01 & 0.57 & 0.66 & 0.55 & 0.48 \\
\hline $\begin{array}{c}\text { Total } \mathrm{N}_{2} \mathrm{O} \text { gas } \\
\text { emissions }\end{array}$ & {$\left[\mathrm{g} N \cdot \mathrm{d}^{-1}\right]$} & 545.2 & 394.2 & 390.1 & 390.3 & 402.8 \\
\hline $\begin{array}{c}\mathrm{N}_{2} \mathrm{O} \text { emitted } \\
\text { from aerobic } \\
\text { zone }\end{array}$ & {$\left[\mathrm{g} \mathrm{N} . \mathrm{d}^{-1}\right]$} & 524.8 & 361.8 & 359.7 & 357.5 & 368.7 \\
\hline $\begin{array}{c}\mathrm{N}_{2} \mathrm{O} \text { produced } \\
\text { by } \mathrm{AOB} \text { in } \\
\text { aerobic zone }\end{array}$ & {$\left[\mathrm{g} \mathrm{N} . \mathrm{d}^{-1}\right]$} & 8858.1 & 4911.9 & 5390.4 & 4743 & 4317.4 \\
\hline $\begin{array}{l}\mathrm{N}_{2} \mathrm{O} \text { produced } \\
\text { by } \mathrm{HB} \text { in } \\
\text { aerobic zone }\end{array}$ & {$\left[\mathrm{g} \mathrm{N} . \mathrm{d}^{-1}\right]$} & -8631.74 & -5183.42 & -5611.5 & -5027.5 & -4623.7 \\
\hline $\begin{array}{c}\mathrm{N}_{2} \mathrm{O} \text { emitted } \\
\text { from anoxic } \\
\text { zone }\end{array}$ & {$\left[\mathrm{g} \mathrm{N} \cdot \mathrm{d}^{-1}\right]$} & 20.5 & 32.4 & 30.4 & 32.8 & 34.1 \\
\hline
\end{tabular}




\begin{tabular}{|c|c|c|c|c|c|c|}
\hline $\begin{array}{c}\mathbf{N}_{\mathbf{2}} \mathbf{O} \text { produced } \\
\text { by AOB in } \\
\text { anoxic zone }\end{array}$ & {$\left[\mathrm{g} \mathrm{N}^{\mathrm{a}} \mathrm{d}^{-1}\right]$} & 14807.5 & 11745.7 & 10829.2 & 12054.2 & 13602 \\
\hline $\begin{array}{c}\mathbf{N}_{\mathbf{2}} \mathbf{O} \text { produced } \\
\text { by HB in } \\
\text { anoxic zone }\end{array}$ & {$\left[\mathrm{g} \mathrm{N} \cdot \mathrm{d}^{-1}\right]$} & -14483.4 & -11079.2 & -10217.1 & -11378.6 & -12892.2 \\
\hline
\end{tabular}

\section{Novelties and limitations of the work}

The current work presents a model that dynamically describes the hydraulic and TSS removal performance of RBF systems used as a primary treatment stage. Compared to the work by Behera et al. (2018), the model presented here enables taking into account the influence of varying hydraulic and system operational parameters, such as belt speed and upstream water level control. This increased level of detail allows a more realistic description of the performance of RBF systems when dynamic wastewater influent conditions are experienced. Furthermore, adopting the empirical model implies that a single RBF unit is used where the upstream water level is always controlled at a high level, regardless of the influent TSS concentration and flow rate. However, when taking into account the hydraulics and operational features of real RBF systems as done by the model proposed here, the influent flow rate has to be split and distributed over several parallel units. This in turn limits the upstream height which can be maintained and, in turn, the TSS removal efficiency, which is proportional to the upstream height through the filtered volume.

Another additional novelty is that the effect of polymer addition on system performance and hydraulics is modelled. The inclusion of the polymer effect is important as polymers have shown their effectiveness in significantly increasing the TSS removal efficiencies in RBF systems (Ebeling et al., 2006; Franchi and Santoro, 2015). This enabled evaluating the plant-wide performance of an on-line control strategy regulating polymer addition on the basis of the belt 
speed manipulated by the upstream water level controller. The implementation of such a control strategy to RBF systems led to a decrease in energy requirements and to an enhancement of methane production compared to the cases when either a primary clarifier or a rotating belt filter system with no polymers were used. Other polymer-adding control strategies could be tested with the proposed model.

Regarding the COD fractionation, an important novelty has been introduced in this work. Behera et al. (2018) imposed a constant removal efficiency for slowly biodegradable COD, heterotrophic biomass and cellulose based on the average values reported by Ruiken et al. (2013), regardless of the dynamics of TSS removal predicted by the model. More realistically, the approach adopted here makes the removal of each particulate component dynamically changing as a function of the predicted TSS removal. It is in fact expected that the removal of particulate COD fractions will vary similarly to the removal of TSS, namely according to the influent TSS load, and according to plant operation as well. Distinguishing between the removal of biodegradable and nonbiodegradable COD in primary treatment systems is important for a full-scale impact assessment of RBF systems as a different loading of biodegradable and non-biodegradable COD to the other treatment units can affect performance parameters such as aeration demand, methane production and effluent quality. It must be pointed out that the implementation of this fractionation is only a step forward towards a more solid and comprehensive understanding of the dynamics of COD removal in PCs and RBF systems. The ratios between the removal efficiencies used in this work present undoubtedly limitations as they are based on only three days of measurements. However, low standard deviations for the ratios were found in almost all cases, despite the fact that the measurements were taken at different times of the year. To consolidate or improve the understanding of the plant-wide effects of applying different primary treatment technologies, a 
larger number of measurements especially with respect to wastewater composition similar to the ones used in this work is needed. Additionally, the effect of different organic carbon loadings to the mainstream activated sludge unit on secondary sludge settleability could be included in the model to improve the impact assessment further. As a matter of fact, as pointed out by Comas et al. (2008), too low food-to-microorganism ratios could be responsible for phenomena of sludge bulking and foaming, while too high effluent nitrates may cause raising sludge in secondary clarifiers. This is especially important to consider when polymer is added to RBF systems in order to achieve high TSS removal. Besides the effect on sludge settleability, worth of being studied is the impact of polymer on the overall WWTP economics, along with energy consumption by the various utilities. However, the plant-wide economic balance of a WWTP depends on so many local factors linked to the location of the plant itself, the source of energy used and the type of equipment employed that a quantification of the total expenses will be very case specific and therefore sometimes misleading.

Another limitation of the work is the mathematical model of the RBF which is specific for systems with a mesh size of $350 \mu \mathrm{m}$ and for a given influent water quality, although it is expected that with another mesh size and/or another influent water quality the model will be able to reproduce the general trends of TSS removal and hydraulic regime. Finally, the increase of cake resistance and of TSS removal efficiency due to polymer addition calibrated in this work is specific of the type of polymer used and could change if another polymer were used instead.

\section{Conclusions and future perspectives}

In this work, a novel dynamic model is presented describing hydraulics and TSS removal of rotating belt filter systems used as primary treatment. The model is able to incorporate the effects of different operational modes and suboptimal operation due to changes in the influent wastewater. 
The validation has shown excellent model fits with the experimental data which confirms that the model can be used extensively with a variety of influent characterizations and polymer additions. The validated model has been employed for a plant-wide assessment aiming at understanding the added value of rotating belt filters as primary treatment step for wastewater treatment plants. Fullscale plant data have been used to determine the removal of the different particulate COD components by the primary clarifier and the rotating belt filter system. It was found that, while RBF technologies have $10 \%$ lower TSS removal efficiency compared to typical primary clarifiers, RBF systems produce a more biodegradable sludge that serves as influent to the anaerobic digester, which consequently produces more methane compared to a digester receiving primary sludge produced by PCs. Additionally, the aeration energy savings are higher compared to the scenario where PCs are used instead. A novel on-line control strategy regulating polymer addition to enhance TSS removal efficiency in RBF systems has been successfully tested and its plant-wide effect was benchmarked against other primary treatment options. It was found that the control strategy can enhance the plant-wide advantages of RBF technologies.

Further application of the validated model may involve the use of the model to support design decisions where the type of machine and the number of RBF units can be selected according to specific influent WWTP dynamics. Future model developments could consider the separate tracking, at plant-wide scale, of the cellulose fiber selectively captured by the RBF using a new state variable, as well as the extension of the current model to the use of metal salts and coagulants such as aluminium or ferric chloride, which have shown potential to efficiently remove colloids as well as soluble phosphorus (Daynouri-Pancino et al., 2018; Ebeling et al., 2006). 


\section{Acknowlegdements}

This work is part of the PIONEER STP project which is funded by Water Joint Programming Initiative, water challenge for a changing world waterworks 2014 co fund call. Dr. Christopher DeGroot acknowledges the funding provided by the Natural Sciences and Engineering Research Council of Canada (NSERC) [RGPIN-2017-04078 and CRDPJ-488704-15]. The contribution of Drs. Francesca Giaccherini and Furqan Khan are greatly appreciated. Dr. Ulf Jeppsson is greatly acknowledged for having provided the codes of the original Benchmark Simulation Model no2.

\section{Bibliography}

Behera, C.R., Santoro, D., Gernaey, K. V., Sin, G., 2018. Organic carbon recovery modeling for a rotating belt filter and its impact assessment on a plant-wide scale. Chem. Eng. J. 334, 1965-1976. https://doi.org/10.1016/j.cej.2017.11.091

Boiocchi, R., Gernaey, K. V., Sin, G., 2017. A novel fuzzy-logic control strategy minimizing N2O emissions. Water Res. 123. https://doi.org/10.1016/j.watres.2017.06.074

Chen, R., Nie, Y., Kato, H., Wu, J., Utashiro, T., Lu, J., Yue, S., Jiang, H., Zhang, L., Li, Y.-Y., 2017. Methanogenic degradation of toilet-paper cellulose upon sewage treatment in an anaerobic membrane bioreactor at room temperature. Bioresour. Technol. 228, 69-76.

Comas, J., Rodríguez-Roda, I., Gernaey, K.V., Rosen, C., Jeppsson, U., Poch, M., 2008. Risk assessment modelling of microbiology-related solids separation problems in activated sludge systems. Environ. Model. Softw. 23, 1250-1261. https://doi.org/10.1016/j.envsoft.2008.02.013

Daynouri-Pancino, F., McLellan, A., Remler, B., Wen, Y., Giaccherini, F., Gupta, M., Sridhar, G., Santoro, D., DeGroot, C.T., Nakhla, G., 2018. Enhancing Carbon Capture In Primary Wastewater Using A Chemically-enhanced Microsieving Technology, in: Proceedings of Ecotechnologies for Wastewater Treatment, 4th IWA Specialized International Conference.

DeGroot, C., Shiekholeslamzadeh, E., Soleymani, A., Santoro, D., Batstone, D., Rosso, D., 2015. 
Understanding Primary Treatment Performance and Carbon Diversion Potential of Rotating Belt Filters Using Computational Fluid Dynamics. Proc. WEFTEC 2015 1249-1262. https://doi.org/10.2175/193864715819556273

DeGroot, C.T., Sheikholeslamzadeh, E., Santoro, D., Sarathy, S., Lyng, T.-O., Wen, Y., Daynouri-Pancio, F., Rosso, D., 2016. Dynamic Modeling of Rotating Belt Filters Enables Design Exploration and Advanced Sizing With Varying Influent Conditions. Proc. WEFTEC 2016 1158-1168. https://doi.org/10.2175/193864716819712791

Domingo-Felez, C., 2017. Establishment and calibration of consensus process model for nitrous oxide dynamics in water quality engineering.

Ebeling, J.M., Welsh, C.F., Rishel, K.L., 2006. Performance evaluation of an inclined belt filter using coagulation/flocculation aids for the removal of suspended solids and phosphorus from microscreen backwash effluent. Aquac. Eng. 35, 61-77. https://doi.org/10.1016/j.aquaeng.2005.08.006

Franchi, A., Santoro, D., 2015. Current status of the rotating belt filtration (RBF) technology for municipal wastewater treatment. Water Pract. Technol. 10, 319-327. https://doi.org/10.2166/wpt.2015.038

Gernaey, K. V., Jeppsson, U., Vanrolleghem, P.A., Copp, J.B., 2014. Benchmarking of Control Strategies for Wastewater Treatment Plants. IWA Publ. London ISBN 9781843391463.

Guo, L., Vanrolleghem, P.A., 2014. Calibration and validation of an activated sludge model for greenhouse gases no. 1 (ASMG1): prediction of temperature-dependent N2O emission dynamics. Bioprocess Biosyst. Eng. 37, 151-163. https://doi.org/10.1007/s00449-013-0978-3

Gupta, M., 2018. Microsieving as a Primary Treatment for Biological Nitrogen Removal from Municipal Wastewater.

Hager, W.H., 2010. Overfalls, in: Wastewater Hydraulics: Theory and Practice. pp. 289-306.

Jeppsson, U., Pons, M.-N., Nopens, I., Alex, J., Copp, J.B., Gernaey, K. V, Rosen, C., Steyer, J.-P., Vanrolleghem, P. a, 2007. Benchmark simulation model no 2: general protocol and exploratory case studies. Water Sci. Technol. 56, 67-78. https://doi.org/10.2166/wst.2007.604

Ni, B.-J., Ye, L., Law, Y., Byers, C., Yuan, Z., 2013. Mathematical modeling of nitrous oxide (N2O) 
emissions from full-scale wastewater treatment plants. Environ. Sci. Technol. 47, 7795-7803. https://doi.org/10.1021/es4005398

Otterpohl, R., Raak, M., Rolfs, T., 1994. A mathematical model for the efficiency of the primary clarification, in: Proceedings of IAWQ 17th Biennial International Conference.

Paulsrud, B., Rusten, B., Aas, B., 2014. Increasing the sludge energy potential of wastewater treatment plants by introducing fine mesh sieves for primary treatment. Water Sci. Technol. 69, 560-565. https://doi.org/10.2166/wst.2013.737

Rivera, D.E., Morari, M., Skogestad, S., 1986. Internal model control. 4. PID controller design. Ind. Eng. Chem. Process Des. Dev. 25, 252-265. https://doi.org/10.1021/i200032a041

Ruiken, C.J., Breuer, G., Klaversma, E., Santiago, T., van Loosdrecht, M.C.M., 2013. Sieving wastewater - Cellulose recovery, economic and energy evaluation. Water Res. 47, 43-48. https://doi.org/10.1016/j.watres.2012.08.023

Sherratt, A., DeGroot, C.T., Straatman, A.G., Santoro, D., 2018a. Numerical Modeling and Control of Solids Separation Using Continuously Moving Fine Mesh Filters. Chem. Eng. Sci. 195, 881-893.

Sherratt, A., DeGroot, C.T., Straatman, A.G., Santoro, D., 2018b. A Numerical Approach for Determining the Resistance of Fine Mesh Filters. Can. Soc. Mech. Eng. Trans.

Sin, G., De Pauw, D.J.W., Weijers, S., Vanrolleghem, P.A., 2008. An efficient approach to automate the manual trial and error calibration of activated sludge models. Biotechnol. Bioeng. 100, 516-528. https://doi.org/10.1002/bit.21769

Sutton, P.M., Rusten, B., Ghanam, A., Dawson, R., Kelly, H., 2008. Rotating Belt Screens: An Attractive Alternative for Primary Treatment of Municipal Wastewater, in: Proceedings of WEFTEC 2008. pp. 1671-1687. https://doi.org/10.2175/193864708788733945 


\section{Highlights}

- Dynamic model for rotating belt filters is successfully calibrated and validated,

- The effect of polymer addition is incorporated in the model,

- Rotating belt filters lead to similar plant-wide impact compared to primary clarifiers,

- Polymer addition improves plant-wide benefits of rotating belt filters over primary clarifiers

- A novel control strategy manipulating polymer addition is found to enhance TSS removal 
Riccardo Boiocchi: Conceptualization, Methodology, Software, Validation, Formal analysis, Investigation, Data Curation, Writing - Original Draft, Visualization

Chitta Ranjan Behera: Software, Methodology, Investigation, Writing - Review \& Editing Christopher DeGroot: Software, Conceptualization, Methodology, Writing - Review \& Editing, Supervision, Funding acquisition

Anthony Sherratt: Conceptualization, Methodology, Software, Validation

Krist Gernaey: Writing - Review \& Editing

Gürkan Sin: Writing - Review \& Editing, Supervision, Project administration

Domenico Santoro: Resources, Writing - Review \& Editing, Supervision, Project administration, Funding acquisition 